\title{
Nuclease resistance of DNA nanostructures
}

\section{Arun Richard Chandrasekaran (D)}

Abstract | DNA nanotechnology has progressed from proof-of-concept demonstrations of structural design towards application-oriented research. As a natural material with excellent self-assembling properties, DNA is an indomitable choice for various biological applications, including biosensing, cell modulation, bioimaging and drug delivery. However, a major impediment to the use of DNA nanostructures in biological applications is their susceptibility to attack by nucleases present in the physiological environment. Although several DNA nanostructures show enhanced resistance to nuclease attack compared with duplexes and plasmid DNA, this may be inadequate for practical application. Recently, several strategies have been developed to increase the nuclease resistance of DNA nanostructures while retaining their functions, and the stability of various DNA nanostructures has been studied in biological fluids, such as serum, urine and cell lysates. This Review discusses the approaches used to modulate nuclease resistance in DNA nanostructures and provides an overview of the techniques employed to evaluate resistance to degradation and quantify stability.

It has been almost 40 years since Ned Seeman published his thoughts on using DNA as a building block for the assembly of nanostructures, a field now called DNA nanotechnology ${ }^{1}$. Seeman's original vision was to use DNA as a framework to crystallize other hard-to-crystallize macromolecules. Early work on DNA-based construction mostly involved the creation of DNA junctions, motifs and devices ${ }^{2-4}$, and, over the past four decades, multiple strategies have been developed to create diverse architectures using $\mathrm{DNA}^{5}$. The library of DNA nanostructures, ranging from the nanometre to the micrometre scale ${ }^{6-8}$, now includes geometric patterns ${ }^{9}$, polyhedral objects ${ }^{10}$, nanoscale bunnies ${ }^{11}$, a box with a lid ${ }^{12}$, a cargo-moving assembly line $\mathrm{e}^{13}$ and even a miniature Mona Lisa ${ }^{14}$. More recently, the focus has moved from proof-of-concept construction using DNA towards the applications of these structures. Being a natural material, DNA nanostructures have found the most use in biological applications ${ }^{15-17}$. Indeed, nanocages built from DNA have been used in drug delivery ${ }^{18}$, reconfigurable DNA devices in biosensing ${ }^{19}$ and DNA structures conjugated to fluorophores and ligands for imaging ${ }^{20}$ and modulating cellular behaviour ${ }^{21}$. Although each of these applications has specific prerequisites, one common requirement is that the DNA nanostructures should remain stable under physiological conditions and be able to withstand degradation by nucleases.

For practical application, DNA nanostructures need to meet certain biostability thresholds. For example, in biosensing, DNA nanodevices must remain intact when mixed with samples (typically, biofluids such as blood, serum and urine), as unpredictable and sudden degradation can lead to false signals. In drug delivery, the biostability of DNA nanostructures is important to protect the drug from harsh physiological conditions until it reaches the destination site in the body. In cellular modulation and bioimaging, DNA nanostructures need to remain largely intact in the cellular or bodily environment to complete their functions (to deliver regulating proteins or accumulate at target tissues, respectively). A major reason for degradation of DNA nanostructures in these conditions is the presence of nucleases (enzymes that degrade nucleic acids). To address this issue, strategies have been developed to modulate the biostability of DNA nanostructures and to increase their suitability for biological applications.

In this Review, I discuss the inherent biostability of DNA nanostructures and the potential use of nanostructures with enhanced nuclease resistance in biological applications. In particular, I focus on the methods developed to tune the nuclease resistance of these structures, the techniques used to analyse their nuclease resistance and the comparative analysis of results from key studies. More general ideas of DNA nanotechnology are beyond the scope of this Review, and interested readers are directed to other reviews covering a range of topics, including biosensing ${ }^{22-24}$, drug delivery $^{25-27}$, bioimaging ${ }^{28-30}$, cellular programming ${ }^{31,32}$ and scaffolding ${ }^{33,34}$. 


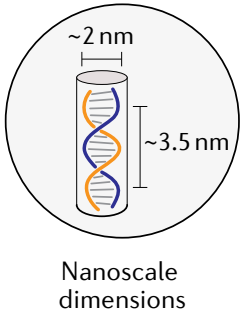

Nanoscale
dimensions

b

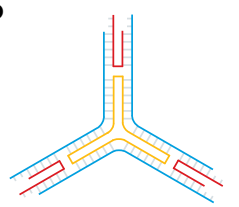

DNA motifs

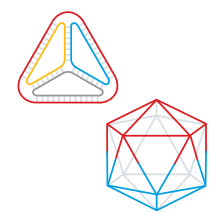

DNA objects

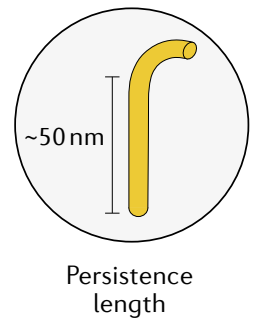

length

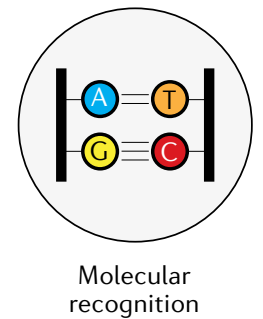

recognition

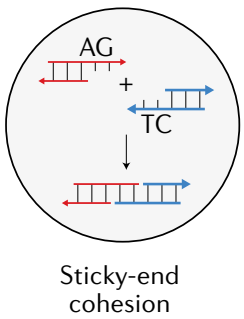

cohesion

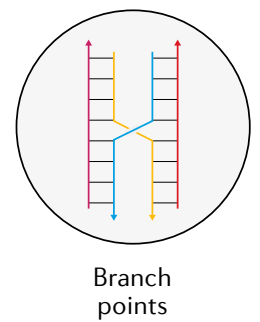

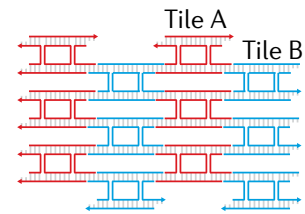

Periodic lattices

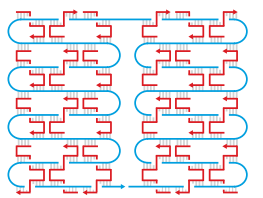

DNA origami

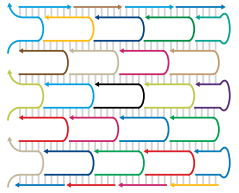

DNA bricks

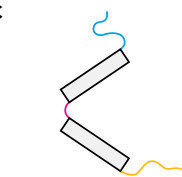

Anti-fuel $\uparrow \mid \widetilde{S}$ Fuel

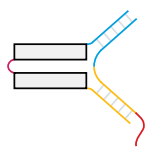

Strand displacement
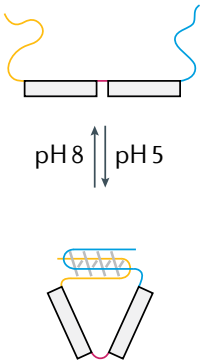

$\mathrm{pH}$

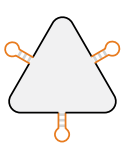

Heatsensitive hairpin

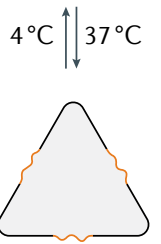

Temperature

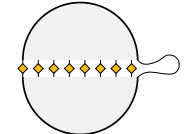

Photocleavable

$\checkmark$ linker

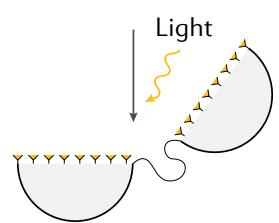

Light

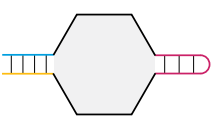

Antigen

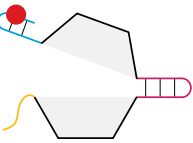

Aptamer reconfiguration

Fig. 1 | Concept, design and construction of DNA nanostructures. a | Properties of DNA that make it suitable for the bottom-up construction of nanostructures. $\mathbf{b}$ | Structural DNA nanotechnology involves the construction of DNA-based structures with different geometries, periodicities or spatial patterns, including motifs ${ }^{36}$, objects such as polyhedra ${ }^{35,144}$, periodic 2D lattices ${ }^{145}$, DNA origami ${ }^{37}$ and DNA bricks ${ }^{38}$. $\mathbf{c}$ |Dynamic DNA nanotechnology involves the construction of DNA devices that operate in response to external stimuli, such as toehold-based strand displacement for nucleic acids ${ }^{107}$, $\mathrm{pH}_{\text {changes }}{ }^{43}$, temperature change $\mathrm{s}^{45}$, light ${ }^{46}$ (ultraviolet or near-infrared, for example) and antigen-aptamer interactions ${ }^{41}$.

\section{Construction using DNA}

DNA is well known as the carrier of genetic information, but is also a natural nanoscale material. The characteristics of DNA that make it a suitable building block for nanoscale architectures include its nanoscale dimensions, persistence length of $\sim 50 \mathrm{~nm}$ (that is, its 'stiffness' for robust construction) and predictable Watson-Crick base pairing, which allows for programmed assembly (FIG. 1a). Furthermore, multidimensional assembly is possible by creating branched DNA structures that can be connected by short single-stranded extensions (sticky ends) to create larger assemblies. Building using DNA has led to two areas of DNA nanotechnology: structural and dynamic. Structural DNA nanotechnology mainly involves the design and construction of DNA-based structures with different geometries, periodicity or spatial patterns (FIG. 1 b). Researchers have created various DNA nanostructures using tile-based assembly ${ }^{35,36}$, DNA origami ${ }^{37}$ and DNA brick strategies ${ }^{38}$. In dynamic DNA nanotechnology, DNA structures are designed to reconfigure upon recognition of external moieties, such as nucleic acids ${ }^{39,40}$, antigens $s^{12,41}$ or ligands ${ }^{40,42}$, or in response to environmental changes, including changes in $\mathrm{pH}^{43,44}$, temperature ${ }^{45}$ or light ${ }^{46,47}$ (FIG. 1 c). Such stimuli-responsive devices are useful in biosensing and as components for triggered release in drug-delivery carriers. Construction principles for DNA nanostructures, assembly strategies and the types of motifs and structures have been discussed elsewhere ${ }^{3,6,48,49}$.

\section{DNA nanotechnology applications}

Developments in DNA nanotechnology have not always adhered to the principle of 'form follows function': in most cases, the function of a DNA nanostructure has followed its form. Demonstrations of the applications of DNA in different fields have increased exponentially in the past decade ${ }^{50,51}$. In materials science, DNA can serve as a copolymer for creating integrated chips ${ }^{52,53}$, pooled DNA libraries are used in data storage and molecular computation $^{54,55}$, and DNA-based moulds have been used for the assembly of metallized nanosheets and electrical nanowires ${ }^{56,57}$. In chemistry, DNA has been used in directing polymer construction ${ }^{58}$ and site-specific chemical reactions ${ }^{59}$, and as scaffolds for the structure 
a Diagnostics

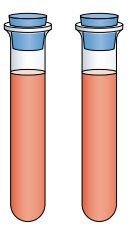

Blood
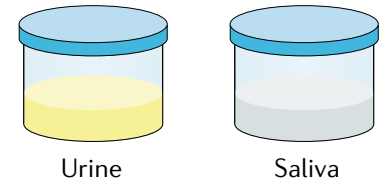

Saliva

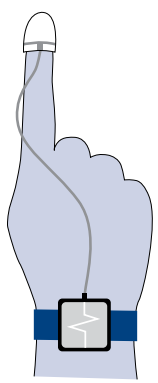

Biosensor

Example: viral RNA detection

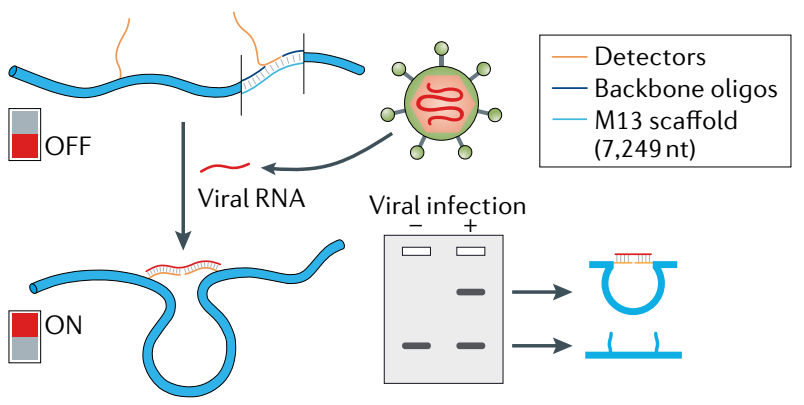

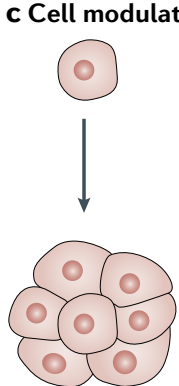

Proliferation

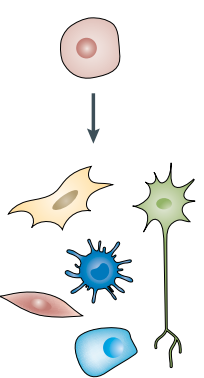

Differentiation

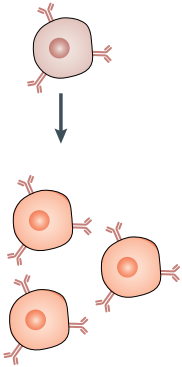

Activation

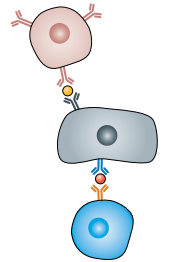

Interaction

Example: structurally tunable extracellular matrix

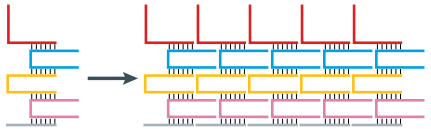
DNA ribbon

Biotin

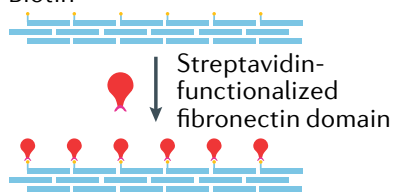

? ? ? ?

Fig. 2 | Biological applications of DNA nanostructures. a | DNA nanostructures can be used in diagnostics for disease detection and monitoring. The example shown is a DNA nanoswitch made from a long M13 scaffold strand and short complementary backbone oligonucleotides. When the single-stranded detectors of the nanoswitch bind to viral RNA, the nanoswitch reconfigures to a looped 'on' state that can be visualized on a gel ${ }^{65}$. b|DNA nanostructures are used as carriers to deliver drugs to specific sites in the body or to cellular compartments. For example, a DNA origami nanotube loaded with thrombin (an anticoagulant) can be targeted towards tumours using a nucleolin-targeting aptamer. On reaching the tumour, the

\section{b Drug delivery}

Drug-encapsulated carrier

(o)
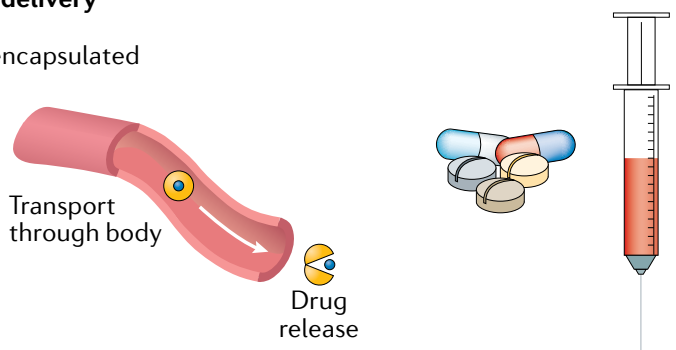

Example: cancer therapeutic

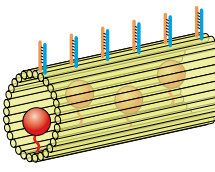

Thrombin-loaded DNA nanotube

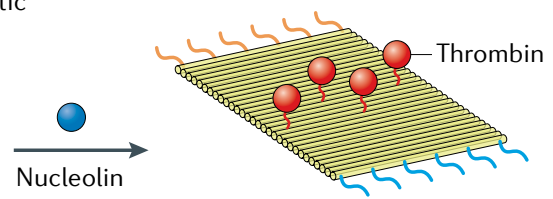

Opening of nanotube for release

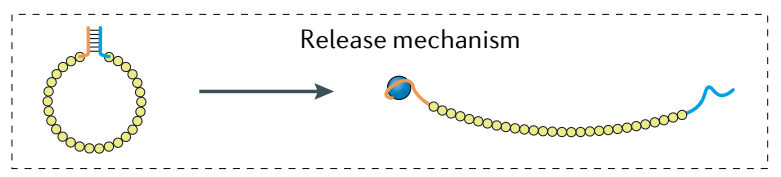

\section{d Imaging}

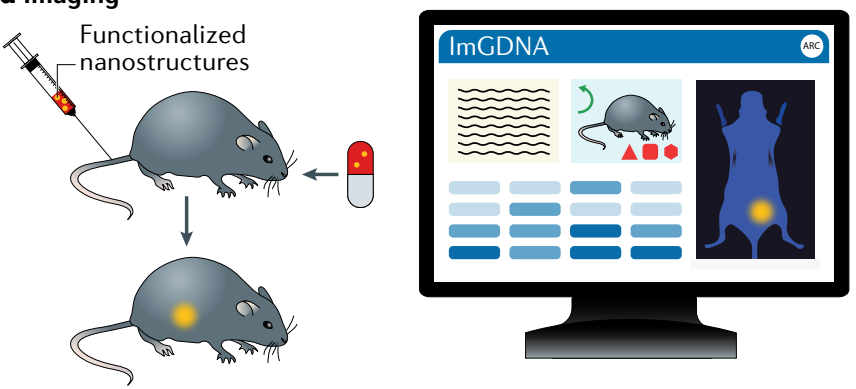

Example: imaging cancer cells

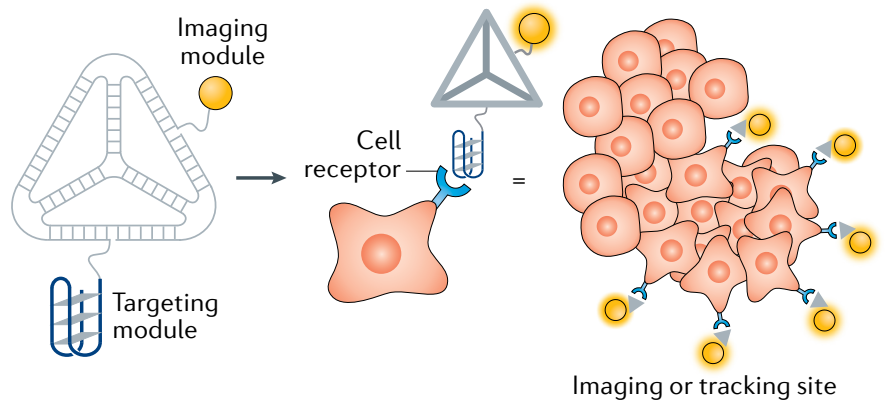

nanotube is opened by interaction of the aptamer with the protein nucleo$\operatorname{lin}^{18}$. c | DNA nanostructures functionalized with specific proteins or ligands can moderate cellular functions. As an example, DNA nanoribbons conjugated to fibronectin protein domains act as an extracellular matrix to enhance cell migration and proliferation ${ }^{79} \cdot \mathbf{d} \mid$ DNA nanostructures functionalized with imaging modules can be used in bioimaging. For example, aptamer-conjugated DNA tetrahedra can be directed specifically to tumour sites in the body and then imaged using the attached fluorophores ${ }^{84}$. Part a (bottom) adapted with permission from REF. ${ }^{19}$, AAAS. Part $\mathbf{b}$ (bottom) adapted from REF. ${ }^{18}$, Springer Nature Limited. Part c (bottom) adapted with permission from REF. ${ }^{79}$, ACS. determination of macromolecules ${ }^{60-62}$. However, most of the recent studies are in biological applications, some of which are briefly discussed below.
Biosensing. DNA-based biosensors are cost-effective and sensitive ${ }^{63,64}$, and are being developed for use as pointof-care diagnostic tools (FIG. 2a). DNA-based sensing 
strategies rely on the recognition event between the DNA nanostructure and a target analyte (such as in nucleic acid and protein sensing) or the conformational change of a DNA-based device (upon sensing, for example, $\mathrm{pH}$ changes or light) ${ }^{22}$. Advantages of DNA nanostructures for biosensing include the highly precise design based on base pairing, the large surface-to-volume ratios and the low-cost synthesis of functionalized DNA strands. So far, DNA nanostructures have been used to detect nucleic acids (including microRNAs ${ }^{19}$, viral RNAs ${ }^{65}$ and pathogenic DNA ${ }^{66}$ ), antigens ${ }^{67}$, antibodies ${ }^{68}$ and small molecules ${ }^{40}$, as well as in sensing in vivo $\mathrm{pH}$ changes ${ }^{43}$.

Drug delivery. In biomedicine, DNA nanostructures have potential utility as drug-delivery carriers (FIG. 2b). DNA provides precise control over the size and geometry of the nanostructures, generating homogeneous populations of drug carriers - a unique advantage over other self-assembling materials and nanoparticles ${ }^{48}$. DNA strands can also be synthesized with functional moieties that are useful for imaging ${ }^{69}$, site-specific targeting ${ }^{70}$ and triggered delivery ${ }^{71}$. Furthermore, DNA nanostructures are biocompatible and exhibit quick renal clearance and minimal toxicity ${ }^{72}$. DNA nanostructures can be tailored to carry various drug cargos, including unmethylated cytosine-phosphate-guanine $(\mathrm{CpG})$ sequences for immunotherapy ${ }^{73}$, monoclonal antibodies as immune checkpoint inhibitors ${ }^{74}$, small interfering $\mathrm{RNA}^{75}$ and antisense oligonucleotides ${ }^{76}$ for gene therapy, proteins for vaccine development ${ }^{77}$ and metallic nanoparticles for photodynamic therapy ${ }^{78}$. Functionalized DNA nanocarriers are, thus, useful in controlling the circulation time, drug-release rate and specificity to a particular target site, resulting in increased delivery efficiency and efficacy of the encapsulated drug ${ }^{25,26}$.

Cell modulation. DNA nanostructures have also been used in modulating cell behaviour and activity ${ }^{79}$ (FIG. 2C). For example, DNA tetrahedra promoted the proliferation and differentiation of stem cells ${ }^{80}$, and peptide-functionalized DNA nanotubes were used in the differentiation of neural stem cells into neurons ${ }^{81}$. In immunotherapy, DNA nanostructures can activate macrophages to provide anti-inflammatory and antioxidative responses $^{82}$. In other studies, DNA nanostructures have been used to influence cell migration, a factor important in wound healing and tumour cell metastasis ${ }^{21}$. The activation of specific cellular pathways by DNA nanostructures and their effects are currently under investigation ${ }^{83}$, which may lead to the development of tools useful in regenerative medicine and gene therapy.

Bioimaging. DNA nanostructures tagged with different imaging modules, such as organic fluorophores, radioactive isotopes and quantum dots, are used for quantitative functional imaging in cells and live model organisms (FIG. 2d). The use of DNA polyhedra and many versions of DNA devices has been demonstrated in imaging tumour-related messenger RNAs ${ }^{84,85}$ and membrane proteins $^{86}$, as well as in tracking cell-entry pathways of drug-carrying DNA nanostructures ${ }^{69}$. Functionalized
DNA nanostructures are also used as imaging standards to calibrate super-resolution microscopes, such as in direct stochastic optical reconstruction microscopy (dSTORM) and stimulated emission depletion $(\mathrm{STED})^{87}$. In addition, DNA-PAINT (DNA-based point accumulation for imaging in nanoscale topography) is being explored for imaging cellular architectures and the real-time trajectories of membrane proteins in live cells ${ }^{88}$.

\section{DNA nanostructure stability}

As a molecule, DNA is highly stable, with a half-life of $\sim 500$ years $^{89}$. However, when assembled into a nanostructure, the stability of DNA can vary, depending on the environment. In each biological application described above, the stability of the assembled DNA nanostructure is a key parameter. To establish the viability of DNA nanostructures in different applications, the stability of these structures is often tested at elevated temperatures ${ }^{90}$, in high-salt and low-salt conditions ${ }^{91}$, and in the presence of nucleases ${ }^{92}$, chaotropic ${ }^{93}$ agents and crowding agents $^{94}$. In most cases, biological operations are tested at the physiological temperature of $37^{\circ} \mathrm{C}$. Depending on the application, stability at $37^{\circ} \mathrm{C}$ for multiple hours might suffice. In terms of the salt and cation concentration, there needs to be a compromise between the conditions required for assembly versus those in the body. In addition, the stability and functionality of DNA structures are also dependent on where they are used, and can be affected by the local density, molecular flexibility and interactions with other molecules present in the sample, such as biological nucleic acids and serum opsonin proteins (which can lead to opsonization) ${ }^{95}$.

A major challenge to the application of DNA-based nanostructures is their susceptibility to attack by a variety of nucleases present in body fluids such as blood, urine and saliva. Nucleases cleave various DNA and RNA substrates (BOX 1), and are involved in biological processes such as DNA repair, replication and recombination ${ }^{96}$. Nuclease activity is also required for structural alterations of nucleic acids, such as in topoisomerization ${ }^{97}$, site-specific recombination ${ }^{98}$ and RNA splicing ${ }^{99}$. Furthermore, nucleases form an integral part of the host immune system in degrading foreign nucleic acids ${ }^{100}$ and have a role in programmed cell death ${ }^{101}$. Although nucleases have important biological functions, they also interfere with the function of DNA-based structures in biological applications, necessitating the study of DNA nanostructure biostability in vivo or in conditions that mimic body fluids. As substitutes for physiological conditions, the stability of DNA nanostructures is tested in vitro using cell and tissue culture media supplemented with mammalian serum (such as fetal bovine serum (FBS)), which contains various nucleases ${ }^{102}$.

Although not all applications require DNA nanostructures to be nuclease resistant, it would be an advantage in most. Exceptions include applications such as biomolecular analysis, in which the molecules under observation are usually isolated and purified before their interactions are tested. Thus, even if they are typically present in a biofluid or tissue, the experiments do not occur in these conditions and are rarely affected by 


\section{Box 1 | Examples of nucleases and their activities}

Nucleases are enzymes that cleave phosphodiester bonds between the sugar and phosphate moieties of DNA. Depending on their activity, nucleases are categorized as exonucleases (cleavage reactions occur at the terminus) or endonucleases (cleavage occurs within the DNA strand). Exonucleases can be further classified as $5^{\prime}$-end processing (such as T7 exonuclease) or $3^{\prime}$-end processing (such as exonuclease III) according to their polarity of consecutive cleavage, with some enzymes preferring 5'-phosphorylated double-stranded DNA (for example, lambda exonuclease). Exonucleases can also be single-strand-specific (for example, exonuclease I) or double-strand-specific (such as exonuclease V). Endonucleases display similar specific activities, with some catalysing cleavage at mismatch sites within double-stranded DNA (for example, T7 endonuclease I), at the site of a ribonucleotide (such as RNase HII) or non-specifically at random sites (such as DNase I). The activity of nucleases can also be sequence-specific or structure-specific.

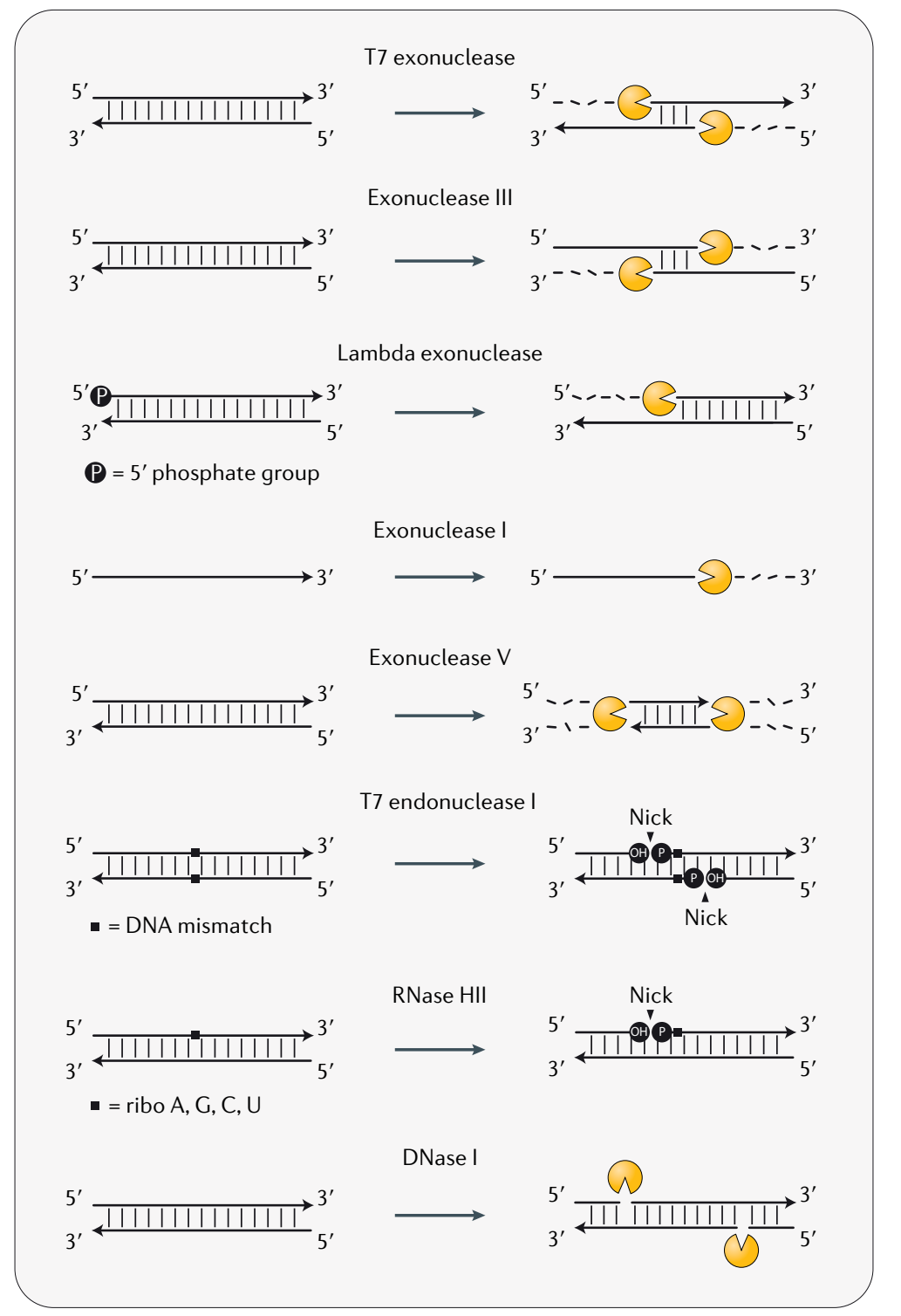

Enzyme unit

The amount of enzyme that will catalyse or produce a specific amount of a substrate or product, respectively, under the specified conditions of an assay. nucleases in the system. There are also some applications in which the native stability of DNA nanostructures is an advantage, or even susceptibility to nuclease degradation might be beneficial (for quick or spontaneous drug release, for example). Nevertheless, in many cases, the stability of DNA nanostructures needs to be enhanced before they are used. In this regard, several strategies are being developed to create nuclease-resistant DNA nanostructures.

\section{Strategies to modulate nuclease resistance}

Strategies to modulate nuclease resistance can begin at the design stage, involve chemical modification or protective coating of the nanostructure, or occur at the point of use by solution treatment, each of which is discussed in more detail in the following sections. Unless otherwise mentioned, the studies discussed below were carried out at the physiological temperature of $37^{\circ} \mathrm{C}$. The structures tested for each strategy, the analysis technique and the resulting nuclease resistance are compiled in TABLE 1.

Design and inherent nuclease resistance. The structural design of DNA nanostructures influences the nuclease resistance. DNA tiles and motifs contain multiple strands hybridized together in a tightly woven fashion. Similarly, larger (and more complex) origami structures contain multiple helical domains packed into bundles (arranged in, for example, square or honeycomb lattices) ${ }^{37,103}$. This close-packed structure in DNA origami and other multi-helix structures is more nuclease resistant than linear duplexes or plasmid DNA ${ }^{104}$ (FIG. 3a). For example, 1 enzyme unit (U) of DNase I completely degraded $65 \mathrm{ng}$ of duplex plasmid DNA (pET24b) in only $5 \mathrm{~min}$, whereas it took $\sim 60 \mathrm{~min}$ to degrade $2 \mathrm{ng}$ of a 24 -helixbundle DNA origami structure ${ }^{104}$. This result indicates the potential of multilayer DNA origami objects as encapsulation agents for use with intercalating drugs, for example. However, DNA nanostructures are required to be hollow to encapsulate cargos such as nanoparticles and proteins. Hollow wireframe structures, such as DNA tetrahedra ${ }^{105}$, have also shown higher stability in $10 \%$ FBS (up to $42 \mathrm{~h}$ ) than linear duplexes, possibly owing to their non-native geometries. The influence of molecular topology on nuclease resistance has also been noted ${ }^{106}$ : a reconfigurable DNA device based on DNA tweezers ${ }^{107}$ was more nuclease resistant in the closed state than in the open state $(\sim 37 \mathrm{~h}$ versus $20 \mathrm{~h}$ in $70 \%$ human serum, respectively), possibly owing to the stacking of two helices side by side in the closed state ${ }^{106}$ (FIG. 3b).

Although, in the above examples, the structures are fortuitously nuclease resistant, this feature can also be intentionally designed into DNA nanostructures. In DNA tetrahedra, placement of restriction sites at specific locations on the duplex edges affected the activity of the enzyme ${ }^{105}$. Structures with the restriction site located near the vertex were protected against degradation by DdeI restriction enzyme, whereas those with the restriction site in the middle fully degraded (FIG. 3c). Another possible strategy to enhance the nuclease resistance is to increase the number of crossovers within the nanostructures. For example, a study ${ }^{92}$ on paranemic crossover (PX) DNA ${ }^{108}$ revealed the exceptional nuclease resistance of the motif, attributed to the continuous crossovers within the structure (FIC. 3d). Compared with duplexes, PX DNA was up to $\sim 2,800$-fold more resistant to four different nucleases (DNase I, exonuclease V, T5 exonuclease and T7 exonuclease), as well as to human serum and urine. Motifs with fewer crossovers 
Table 1 | Reported nuclease resistance of various DNA nanostructures

\begin{tabular}{|c|c|c|c|c|}
\hline Strategy & Structure (size) & Test environment & $\begin{array}{l}\text { Analysis } \\
\text { technique }\end{array}$ & Stability metrics \\
\hline \multicolumn{5}{|l|}{ Design } \\
\hline $\begin{array}{l}\text { Close-packed } \\
\text { helices }^{104}\end{array}$ & 24-HB (100 nm) & $1 \cup$ DNase I & AGE & $\begin{array}{l}\text { Duplex plasmid DNA: degraded in } 5 \mathrm{~min} \\
\text { Close-packed helices: degraded in } 60 \mathrm{~min}\end{array}$ \\
\hline Topology $y^{106}$ & Tweezers ( 14 nm) & $70 \%$ human serum & PAGE, FRET & $\begin{array}{l}\text { Closed state: degraded in } \sim 37 \mathrm{~h} \\
\text { Open state: degraded in } \sim 20 \mathrm{~h}\end{array}$ \\
\hline Increased crossovers ${ }^{92}$ & $\begin{array}{l}\text { PX, DX and duplex DNA } \\
(\sim 13 \mathrm{~nm})\end{array}$ & $\begin{array}{l}\text { DNase I, exonuclease V, T5 } \\
\text { and T7 exonucleases (for } 1 \mathrm{~h} \text { ); } \\
10 \% \text { FBS, human serum and } \\
\text { urine (for } 24 \mathrm{~h} \text { ) }\end{array}$ & PAGE & $\begin{array}{l}\text { PX: 100\% intact } \\
\text { DX: } 0-30 \% \text { intact } \\
\text { Duplex: almost fully degraded }\end{array}$ \\
\hline \multicolumn{5}{|l|}{ Solution treatment } \\
\hline $\begin{array}{l}\text { Minor-groove binders } \\
(\text { DAPII) }\end{array}$ & Pentagonal bipyramid ( 40 nm) & $10 \%$ mouse serum & AGE & $\begin{array}{l}\text { Native structures: stable for } 3 \mathrm{~h} \\
\text { With groove binders: stable for } 24 \mathrm{~h}\end{array}$ \\
\hline $\begin{array}{l}\text { Ethylenediamine } \\
\text { buffer }^{111}\end{array}$ & Tetrahedron (14nm) & $0.5 \cup$ DNase I & PAGE & $\begin{array}{l}\text { In TAE } / \mathrm{Mg}^{2+} \text { buffer: } 0 \% \text { intact } \\
\text { In ethylenediamine buffer: } \sim 100 \% \text { intact }\end{array}$ \\
\hline \multicolumn{5}{|l|}{ Chemical modifications } \\
\hline Ligation $^{105,113}$ & Tetrahedron (7 nm), prism (7 nm) & $10 \%$ FBS & PAGE & $\begin{array}{l}\text { ssDNA: degraded in } 0.8 \mathrm{~h} \\
\text { Ligated tetrahedron: degraded in } 42 \mathrm{~h}\end{array}$ \\
\hline $\begin{array}{l}\text { Crosslinking (click } \\
\text { chemistry) }\end{array}$ & Nanotube $(\sim 30 \mathrm{~nm})$ & Exonuclease I for $3 \mathrm{~h}$ & AGE & $\begin{array}{l}\text { Native: fully degraded } \\
\text { Crosslinked: partially degraded }\end{array}$ \\
\hline L-DNA $^{117}$ & $\begin{array}{l}\text { 4-Arm junction }(\sim 5 \mathrm{~nm}) \text {, } \\
\text { nanotube }(30-70-\mathrm{nm} \text { width, } \\
\sim \mu \mathrm{m} \text { long) }\end{array}$ & $\begin{array}{l}2 U \mu \mathrm{l}^{-1} \text { (exonuclease I) or } \\
20 \mathrm{Ul}^{-1} \text { (exonuclease III) for } \\
45 \mathrm{~min}\end{array}$ & PAGE, AFM & $\begin{array}{l}\text { Native junction: completely degraded } \\
\text { L-DNA junction: almost fully intact }\end{array}$ \\
\hline $\begin{array}{l}\text { Unnatural base } \\
\text { pairs }^{118}\end{array}$ & 6-Arm junction ( 14 nm) & T7 exonuclease for $12 \mathrm{~h}$ & PAGE & $\begin{array}{l}\text { Native structure: completely degraded } \\
\text { Modified: partially degraded }\end{array}$ \\
\hline \multicolumn{5}{|l|}{ Protective coatings } \\
\hline $\begin{array}{l}\text { HSA-DNA dendrite } \\
\text { conjugates }^{120}\end{array}$ & Cube $(\sim 7 \mathrm{~nm})$ & Media $+10 \%$ FBS for $48 \mathrm{~h}$ & PAGE & $\begin{array}{l}\text { ssDNA: } 33 \text {-min half-life } \\
\text { Protected cube: up to } 22 \text {-h half-life }\end{array}$ \\
\hline $\begin{array}{l}\text { Dendritic } \\
\text { oligonucleotides }^{121}\end{array}$ & DNA brick ( $50 \mathrm{~nm})$ & $100 \mathrm{Uml}^{-1}$ DNase I for $1 \mathrm{~h}$ & AGE & $\begin{array}{l}\text { Native: fully degraded with } 5 \mathrm{U} \mathrm{ml}^{-1} \\
\text { Coated: } 50 \% \text { degraded with } 100 \mathrm{Uml}^{-1}\end{array}$ \\
\hline $\begin{array}{l}\text { PEGylated lipid } \\
\text { bilayer }^{122}\end{array}$ & Octahedron (76nm) & $20 U$ DNase I for $24 \mathrm{~h}$ & Fluorescence & $\begin{array}{l}\text { Without envelope: } \sim 30 \% \text { intact } \\
\text { With envelope: } \sim 85 \% \text { intact }\end{array}$ \\
\hline $\begin{array}{l}\text { Cationic } \\
\text { polysaccharides }^{123}\end{array}$ & $\begin{array}{l}\text { Origami rod }(350 \mathrm{~nm}) \text {, bottle } \\
(50 \times 25 \mathrm{~nm})\end{array}$ & $10 \mathrm{Uml}^{-1}$ DNase I & AGE, TEM & $\begin{array}{l}\text { Native structure: stable for } 1 \mathrm{~h} \\
\text { With protection: stable for } 24 \mathrm{~h}\end{array}$ \\
\hline $\begin{array}{l}\text { PEG-polylysine block } \\
\text { copolymers }^{126}\end{array}$ & $\begin{array}{l}\text { Rectangle }(\sim 100 \mathrm{~nm}), 6-\mathrm{HB} \\
(\sim 600 \mathrm{~nm}) \text {, truss }(\sim 20 \times 200 \mathrm{~nm}) \\
24-\mathrm{HB}(\sim 100 \mathrm{~nm})\end{array}$ & $\begin{array}{l}1 \mu \mathrm{l} \text { of } 16 \mathrm{Uml}^{-1} \text { DNase I for } \\
16 \mathrm{~h} \\
1 \mu \mathrm{l} \text { of } 2,000 \mathrm{Uml}^{-1} \text { DNase I } \\
\text { for } 16 \mathrm{~h}\end{array}$ & TEM, AFM & $\begin{array}{l}\text { Native: } 0 \% \text { intact } \\
\text { Protected: } 100 \% \text { intact }\end{array}$ \\
\hline $\begin{array}{l}\text { Oligolysine-PEG } \\
\text { copolymer }^{124}\end{array}$ & Origami barrel ( 60nm) & Media $+10 \%$ FBS & AGE, TEM & $\begin{array}{l}\text { Native structure: } 5 \text {-min half-life } \\
\text { With oligolysine: } 50 \text {-min half-life }\end{array}$ \\
\hline
\end{tabular}


Table 1 (cont.)| Reported nuclease resistance of various DNA nanostructures

\begin{tabular}{|c|c|c|c|c|}
\hline Strategy & Structure (size) & Test environment & $\begin{array}{l}\text { Analysis } \\
\text { technique }\end{array}$ & Stability metrics \\
\hline \multicolumn{5}{|c|}{ Protective coatings (cont.) } \\
\hline $\begin{array}{l}\text { Crosslinking of } \\
\text { oligolysine coating }{ }^{125}\end{array}$ & Origami barrel (60-90 nm) & $1 \cup \mu \mathrm{l}^{-1}$ DNase I & AGE, TEM & $\begin{array}{l}\text { Without crosslinking: } 16 \text {-min half-life } \\
\text { With crosslinking: } \sim 66 \text {-h half-life }\end{array}$ \\
\hline $\begin{array}{l}\text { BSA-dendron } \\
\text { conjugates }^{127}\end{array}$ & $60-\mathrm{HB}(20 \times 20 \times 33 \mathrm{~nm})$ & $\begin{array}{l}10 U \text { DNase I in } 20 \mu \text { reaction } \\
\text { for } 1 \mathrm{~h} \text { at RT }\end{array}$ & AGE & $\begin{array}{l}\text { Native: }<20 \% \text { intact } \\
\text { With protection: } \sim 100 \% \text { intact }\end{array}$ \\
\hline Peptoids $^{128}$ & Octahedron (29nm) & $15 \mu \mathrm{g} \mathrm{ml}^{-1}$ DNase I for $30 \mathrm{~min}$ & AGE, TEM & $\begin{array}{l}\text { Native structure: completely degraded } \\
\text { With protection: almost fully intact }\end{array}$ \\
\hline Silica coating ${ }^{130}$ & $\begin{array}{l}\text { 24-HB }(\sim 100 \mathrm{~nm}) \\
\text { 13-Helix ring }(66 \mathrm{~nm})\end{array}$ & $\begin{array}{l}4 \mathrm{Uml}^{-1} \text { DNase I for } 3 \mathrm{~h} \\
0.5 \mathrm{Uml}^{-1} \text { DNase I for } 3 \mathrm{~h}\end{array}$ & AGE, TEM & $\begin{array}{l}\text { Native structure: completely degraded } \\
\text { Silicified structures: almost fully intact }\end{array}$ \\
\hline
\end{tabular}

Unless mentioned otherwise, listed experiments were conducted at $37^{\circ} \mathrm{C}$. AFM, atomic force microscopy; AGE, agarose gel electrophoresis; BSA, bovine serum albumin; DAPI, 2-(4-amidinophenyl)-1H-indole-6-carboxamidine; DX, double crossover; EDTA, ethylenediaminetetraacetic acid; FBS, fetal bovine serum;

FRET, Förster resonance energy transfer; HSA, human serum albumin; $n$-HB, $n$-helix bundle; PAGE, polyacrylamide gel electrophoresis; PEG, polyethylene glycol;

PX, paranemic crossover; RT, room temperature; ssDNA, single-stranded DNA; TAE, tris-acetate-EDTA; TEM, transmission electron microscopy; UV, ultraviolet.

\section{Restriction enzyme}

An enzyme that recognizes

a specific, short nucleotide

sequence and cuts the DNA

only at that specific site, which

is known as a restriction site or

target sequence.

Paranemic crossover (PX) DNA

A four-stranded DNA motif that consists of two adjacent double-helical DNA domains connected by strand crossovers at every possible point between two side-by-side helices. showed reduced stability, suggesting that the increased number of crossovers in PX DNA confers additional biostability.

Solution treatment and nuclease inhibitors. The effect of nucleases on the lifetime of DNA nanostructures can be minimized by using nuclease inhibitors or changing the environment in which the structures are assembled or used. One approach is to expose the samples to conditions that denature the nucleases. For example, DNA origami nanostructures (an octahedron, nanotube and nanorod) incubated in RPMI cell culture medium supplemented with $10 \%$ FBS degraded completely within $24 \mathrm{~h}\left(\mathrm{REF}^{109}\right)$. By contrast, heating the FBS to $75^{\circ} \mathrm{C}$ for

\section{b Topology}

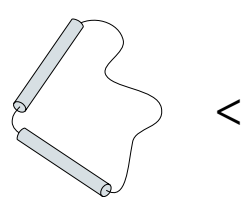

Open

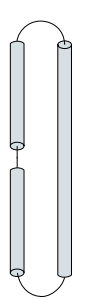

Closed

Single helix

Multilayer objects

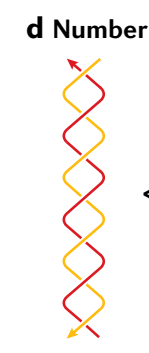

Duplex

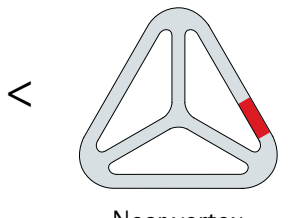

Near vertex

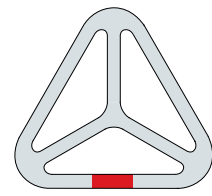

Middle c Location of restriction sites

Fig. 3 | Nanostructure designs for enhanced nuclease resistance. a | Close-packed helices, as used in DNA origami or DNA bundles ${ }^{104}$, are more nuclease resistant than linear duplexes or plasmid DNA. b | The biostability of nanostructures is also dependent on the topology, as seen in DNA tweezers ${ }^{106}$, for which the closed state is more nuclease resistant than the open state. $\mathbf{c}$ |Changing the location of enzyme-specific sequences such as restriction sites $^{105}$ also influences the nuclease resistance. $\mathbf{d}$ | DNA motifs with a greater number of crossovers exhibit higher nuclease resistance ${ }^{92}$. For example, paranemic crossover (PX) DNA is more nuclease resistant than double crossover (DX) DNA.
10 min before addition to the cell culture medium prolonged the nanostructure lifetime in the medium (with almost no degradation), owing to the inactivation of nucleases in the serum (FIC. 4a). However, heating the FBS might also have a more general effect on serum proteins, which could affect cell growth and phenotype.

Nuclease inhibitors can also be used to reduce the effect of nucleases in solution. For example, the addition of a tenfold molar excess of actin, a known nuclease inhibitor, extended the lifetime of DNA nanostructures against DNase I (REF. ${ }^{109}$ ) (FIG. 4b). In contrast to heat treatment of FBS, which is incompatible with in vitro tissue culture, inclusion of actin (up to $200 \mathrm{nM}$ ) had no observable effect on cell growth and viability. In other cases, compounds that restrict access to the minor groove of double-stranded DNA can competitively inhibit DNase I activity (FIG. 4C). In a study reported in a recent preprint article, the efficiency of different classes of minor-groove binders on reducing the nuclease degradation of wireframe DNA origami structures (a two-helix pentagonal bipyramid) was tested ${ }^{110}$. Diamine 2-(4-amidinophenyl)- $1 H$-indole-6-carboxamidine (DAPI) was the most potent stabilizer, increasing the protection of structures in $10 \%$ mouse serum to $24 \mathrm{~h}$, compared with the 3 -h stability of native structures.

The conditions in which the nanostructures are assembled also affect their biostability. DNA tetrahedra assembled in ethylenediamine buffer exhibited enhanced nuclease resistance compared with those assembled in one of the most commonly used buffers, tris-acetate-EDTA/ $\mathrm{Mg}^{2+}\left(\mathrm{TAE} / \mathrm{Mg}^{2+}\right.$; where EDTA is ethylenediaminetetraacetic acid) ${ }^{111}$ ) (FIG. 4d). In a 10-min reaction with DNase I, DNA tetrahedra assembled in TAE buffer completely degraded, whereas almost no digestion occurred in the ethylenediamine buffer. The increased resistance in ethylenediamine is possibly due to the absence of metal ions needed for enzymatic activity. Although this strategy increases the lifetime of DNA nanostructures in the presence of nucleases, further studies are needed to validate the compatibility of this buffer for the assembly of different DNA nanostructures and the toxicity of such organic compounds in vivo. For some structures, the inherent assembly 


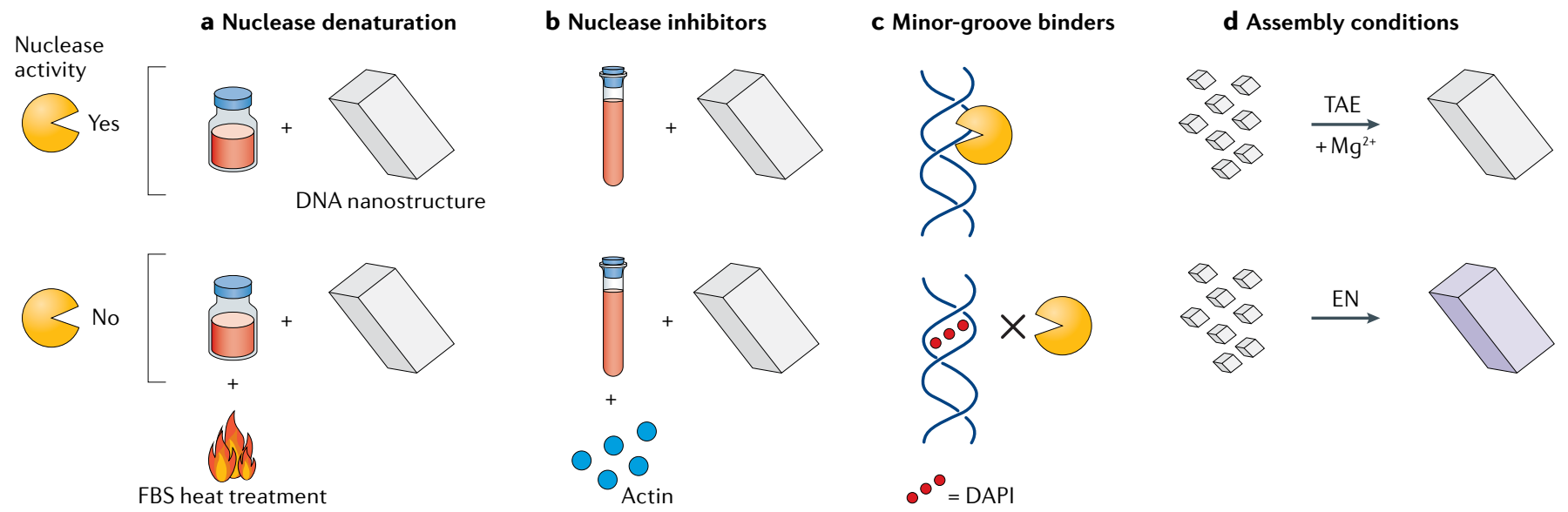

Fig. 4 | Solution treatment to prevent nuclease degradation. a | Heating serum samples denatures the nucleases, thus rendering them inactive ${ }^{109} \cdot \mathbf{b} \mid$ The addition of nuclease inhibitors, such as actin, to samples reduces nuclease activity, thus protecting DNA nanostructures from degradation ${ }^{109} . \mathbf{c}$ | The addition of minor-groove binders such as DAPI (2-(4-amidinophenyl)-1H-indole-6-carboxamidine) occludes nuclease binding to DNA nanostructures, thus minimizing degradation $^{110} . \mathbf{d} \mid$ The assembly conditions can be varied to increase the biostability. For example, DNA nanostructures were minimally degraded when assembled in ethylenediamine (EN) buffer, but degraded fully when assembled in the commonly used buffer tris-acetate-EDTA (TAE) with $\mathrm{Mg}^{2+}\left(\mathrm{REF}^{111}\right)$. EDTA, ethylenediaminetetraacetic acid; FBS, fetal bovine serum.

units can be provided as fuel in the solution to heal the nanostructures as they are degraded by nucleases, thus reversing the degradation process. This approach was demonstrated using micrometre-scale DNA nanotubes assembled from double crossover (DX) tiles ${ }^{112}$. The DNA nanotubes degraded within $24 \mathrm{~h}$ in $10 \%$ FBS-supplemented medium. Upon introducing the monomer DX tiles into the solution, these units incorporated into the damaged regions of the DNA nanotubes and, thus, repaired the nanotubes, prolonging their lifetime to $96 \mathrm{~h}$.

Chemical modifications. Numerous studies have reported chemical modifications to DNA nanostructures to enhance nuclease resistance. These modifications strengthen the weaknesses in the nanostructure design, making DNA nanostructures less susceptible to nuclease digestion. For example, the presence of single-stranded segments and internal nicks in DNA nanostructures make them vulnerable to nuclease attacks ${ }^{105}$. Once constructed, internal nicks can be eliminated by covalently linking the strand termini by ligation or crosslinking. Reducing the number of free termini by enzymatic ligation was effective in enhancing the nuclease resistance of DNA tetrahedra ${ }^{105}$ and prisms ${ }^{113}$, increasing the mean lifetime of these structures to $\sim 42 \mathrm{~h}$ and $\sim 200 \mathrm{~h}$, respectively, in 10\% FBS (FIG. 5a). Crosslinking the helices within nanostructures by azide-alkyne click reactions has also helped DNA nanostructures to withstand nuclease degradation ${ }^{114}$ (FIG. 5b). Crosslinked DNA nanotubes had greater protection against exonuclease I compared with native structures. In another example, thymidines were positioned in close proximity within DNA origami nanostructures and crosslinked using ultraviolet light, leading to the site-specific formation of covalent bonds and cyclobutane pyrimidine dimers ${ }^{115}$ (FIG. 5c). The additional covalent bonds increased the lifetime of the nanostructures from $10 \mathrm{~min}$ (for native structures) to $60 \mathrm{~min}$ in the presence of $0.4 \mathrm{U} \mathrm{ml}^{-1}$ DNase I.

In addition to post-assembly modifications, the inherent stability of nanostructures can be increased by modifying the DNA backbone and nucleobases of component strands. In one example, DNA strand termini were functionalized with hexaethylene glycol and hexanediol groups, and then used in building DNA prisms ${ }^{113,116}$ (FIG. 5d). These structures had a lifetime of 55-62 h in FBS-supplemented culture medium, whereas the unmodified native DNA nanostructures degraded in less than $18 \mathrm{~h}$. Another route to enhancing nuclease resistance is by using modified DNA as the component strands for assembly. Two-dimensional DNA arrays and a DNA tetrahedron built using L-DNA were more resistant to nucleases than their D-DNA (that is, regular right-handed DNA) counterparts ${ }^{117}$ (FIG. 5e). The L-DNA structures remained almost fully intact after treatment with exonuclease I and exonuclease III for $45 \mathrm{~min}$, whereas the native structures fully degraded. In another study, six-arm junctions containing unnatural DNA base pairs (2-thiothymidine:A and 5-methyl-isocytidine:isoG) were only partially digested by $\mathrm{T} 7$ exonuclease after $12 \mathrm{~h}$, whereas the unmodified junction completely degraded ${ }^{118}$ (FIG. 5f). In the context of chemical modifications, a less-explored option is the incorporation of $2^{\prime}-5^{\prime}$-linked oligonucleotides into nucleic acid nanostructures to enhance resistance against ribonucleases ${ }^{119}$.

Protective coatings. Modifying the component strands also allows the nanostructures to be coated with a protective layer that resists nuclease activity. In one such strategy, the component strands of DNA cubes were modified with dendritic alkyl chains to form amphiphiles that bind to human serum albumin (HSA) ${ }^{120}$ (FIG. 6a). In stability tests in Dulbecco's modified Eagle 


\section{Dendron}

Monodisperse, wedge-shaped branched molecule with multiple terminal groups and a single reactive function at the focal point.

a Ligation

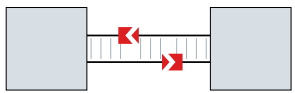

- 5 ' end

$43^{\prime}$ end

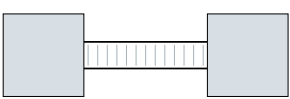

medium supplemented with $10 \%$ FBS, single-stranded DNA modified with a dendritic alkyl chain and conjugated to HSA had a half-life of $33 \mathrm{~min}$, increasing to $10 \mathrm{~h}$ for a DNA cube with four such modified strands conjugated to HSA and to $22 \mathrm{~h}$ for a DNA cube with eight HSA-conjugated strands. A protective coating formed from dendritic oligonucleotides that feature at one end a three-pronged group attached to three oligonucleotides has also been demonstrated ${ }^{121}$ (FIG. 6b). The stem of the dendritic oligonucleotide can hybridize to singlestranded handles on DNA brick structures, forming a thick DNA coating. DNA bricks with this coating were only $50 \%$ digested with $100 \mathrm{U} \mathrm{ml}^{-1}$ of DNase I in $1 \mathrm{~h}$, whereas native structures were fully digested with only $5 \mathrm{U} \mathrm{ml}^{-1}$ of the nuclease. In another example, a DNA octahedron was enveloped by a PEGylated lipid bilayer, which increased the percentage of intact structures from $30 \%$ to $85 \%$ when incubated in $20 \mathrm{U}$ DNase I for $24 \mathrm{~h}$ (REF. ${ }^{122}$ ) (FIG. 6C).

The high negative charge of DNA can also be exploited to create a polycationic coating through electrostatic interactions with DNA. For example, cationic polysaccharides such as chitosan and synthetic linear polyethyleneimine were used to coat DNA origami rods, yielding structures that were stable in $10 \mathrm{U} \mathrm{ml}^{-1}$ of DNase I for $24 \mathrm{~h}$ (REF. ${ }^{123}$ ) (FIG. 6d). Using a similar strategy, DNA origami barrels were coated with oligolysines to increase the lifetime of nanostructures in culture media to $50 \mathrm{~min}$, compared with $5 \mathrm{~min}$ for native structures under the same conditions ${ }^{124}$. Furthermore, conjugating PEG to these oligolysines ${ }^{124}$ (FIG. 6e) or crosslinking the oligolysine-PEG coating using glutaraldehyde ${ }^{125}$ (FIG. 6f) further increased the nuclease resistance of these nanostructures to $\sim 36 \mathrm{~h}$ in culture medium and $\sim 66 \mathrm{~h}$ in $1 \mathrm{U}_{\mu} \mathrm{l}^{-1}$ of DNase I, respectively. PEG-conjugated polylysines have also been used for coating DNA origami structures, forming DNA origami polyplex micelles ${ }^{126}$. The electrostatic interactions between PEG-polylysine and DNA enabled the origami structure to remain intact for $16 \mathrm{~h}$ in the presence of DNase I and in FBS-supplemented RPMI medium, whereas native structures completely degraded. This protection strategy was also compatible with functionalized DNA origami structures, causing no loss of functional moieties when applied to six-helix bundles decorated with gold nanoparticles or streptavidin-coated quantum dots.

Peptides and proteins can also be used to coat DNA nanostructures. In one example, a protein corona was formed around DNA origami nanostructures to make them nuclease resistant ${ }^{127}$. Protein-dendron conjugates were created by anchoring bovine serum albumin to a dendron through a cysteine-maleimide bond (FIG. 6g). The dendron part of the conjugate functions as a cationic binding domain that electrostatically attaches to the negatively charged DNA origami surface. Almost $100 \%$ of the protected DNA origami structures remained

\section{b Crosslinking (click chemistry)}

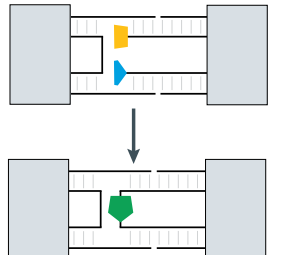

= Alkyne

$\longrightarrow \mathrm{N}_{3}$ Azide

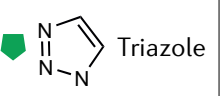

c Crosslinking (UV irradiation)
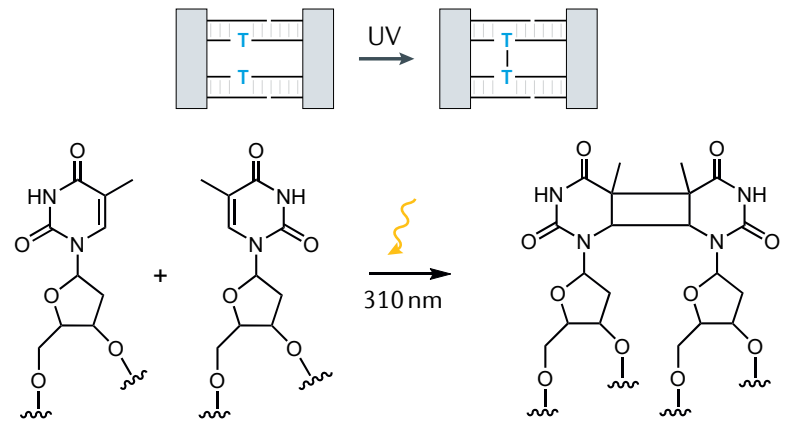

f Unnatural base pairs

e L-DNA
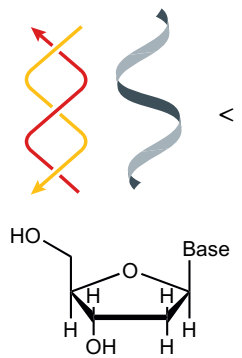

Normal D-form
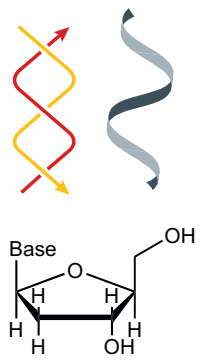

L-form

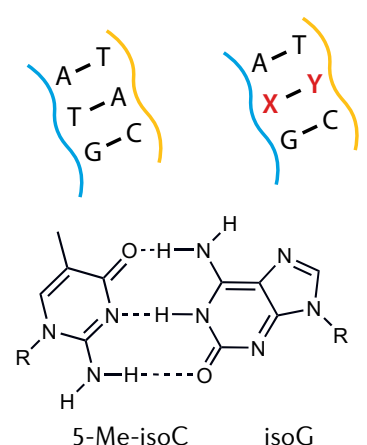

Fig. 5 | Chemical modifications to enhance nuclease resistance. Various chemical modifications have been demonstrated to increase the nuclease resistance of DNA structures. These approaches include ligation of strand termini ${ }^{105}$ (part a); crosslinking of component strands by click chemistry ${ }^{114}$ (part b); crosslinking of strands through the formation of a thymidine dimer under ultraviolet (UV) irradiation ${ }^{115}$ (part c); the introduction of terminal functional groups, such as hexaethylene glycol and hexanediol ${ }^{113}$ (part d); the use of L-DNA ${ }^{117}$ (part e); and the use of unnatural base pairs (where 5-Me-isoC is 5-methyl-isocytidine; part f $)^{118}$. 


\section{REVIEWS}

a HSA-DNA dendrite

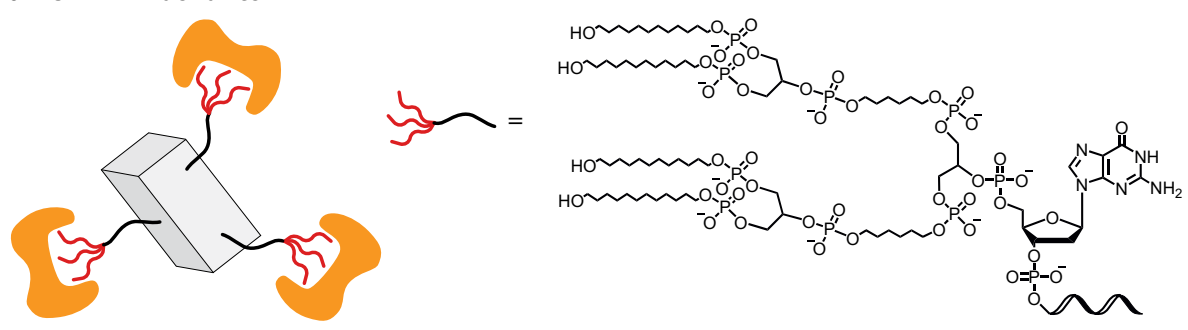

b Dendritic oligonucleotides

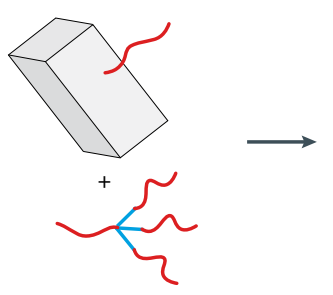

d Polycation shell
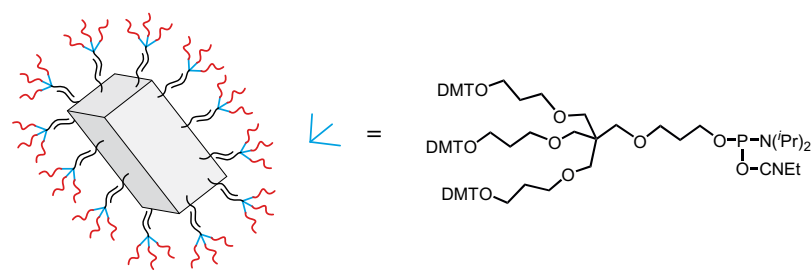

e Oligolysine-PEG coating

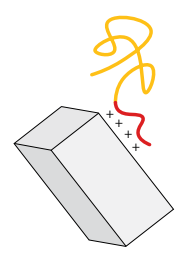

$\mathcal{Z}=\underbrace{\text { 罚 }}_{\text {Oligolysine }\left(\mathrm{K}_{10}\right)}$ $\mathrm{K}_{10}-\mathrm{PEG}_{5 \mathrm{~K}}$

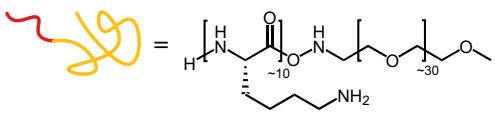

c PEGylated lipid bilayer

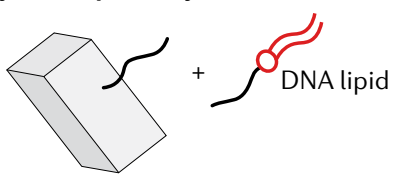

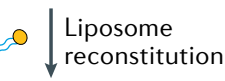

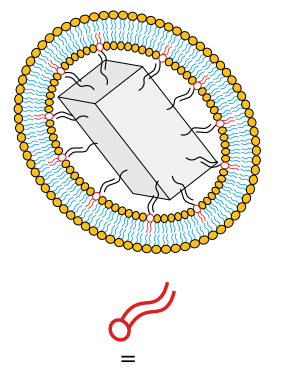

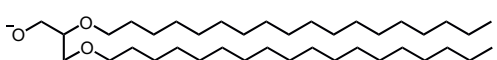

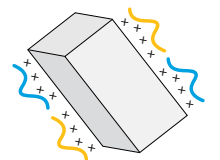

$2_{+}^{+}=\overbrace{\mathrm{H}}]_{n}$

LPEI

$\mathrm{C}_{\mathrm{H}}^{+}=$ Chitosan

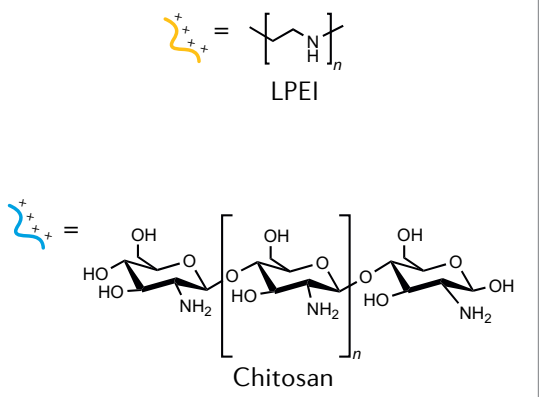

g BSA-dendron

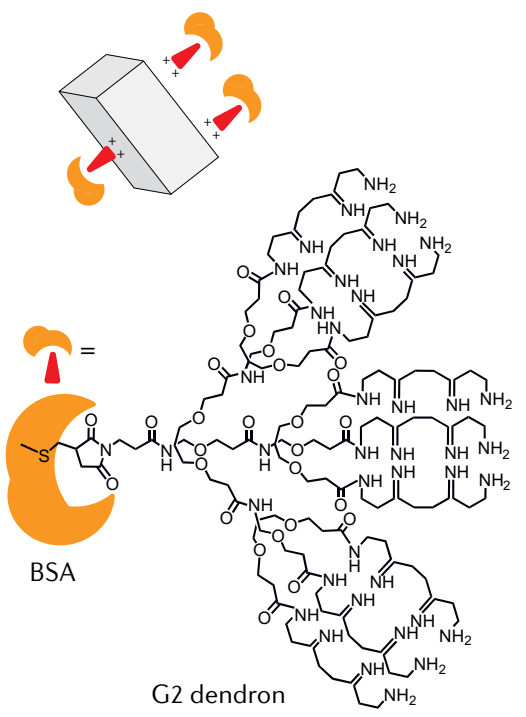

f Glutaraldehyde crosslinking

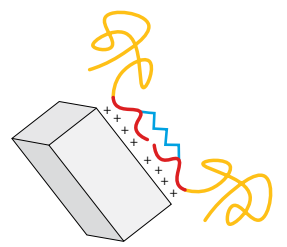

$\overbrace{H}^{\stackrel{O}{l}}$

Glutaraldehyde $\rightarrow$ CONS

$\overbrace{\mathrm{NH}_{2} \mathrm{H}_{2} \mathrm{~N}}^{+}$Crosslinked amines

Free amines h DNA peptoid

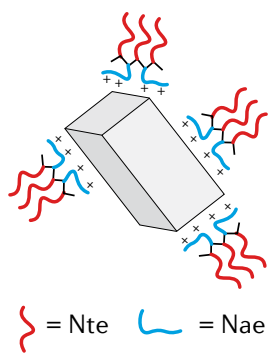

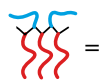

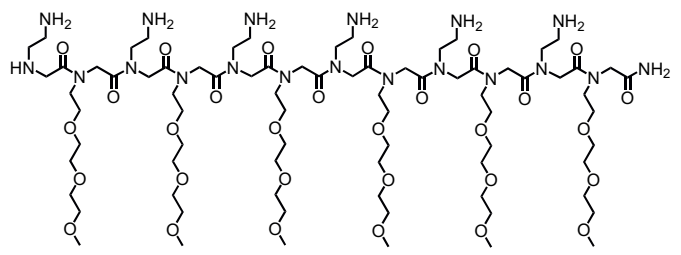

i Silica coating

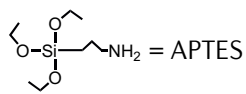

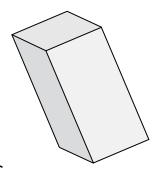

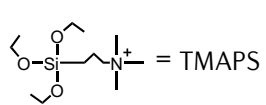
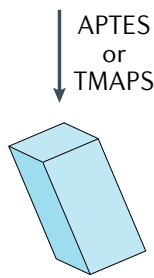

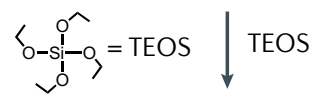


4 Fig. 6 | Protective coatings to enhance nuclease resistance. Various protective coatings have been developed to increase the nuclease resistance of DNA nanostructures. These approaches include a coating formed through the complexation of human serum albumin (HSA) and DNA dendrites ${ }^{120}$ (part a); coating nanostructures with dendritic DNA through hybridization to DNA handles ${ }^{121}$ (part b); a PEGylated (where PEG is polyethylene glycol) lipid bilayer protective envelope ${ }^{122}$ (part c); the charge-based accumulation of a polycationic shell ${ }^{123}$ (part d); an oligolysine-PEG coating ${ }^{124}$ (part e); a coating formed through glutaraldehyde crosslinking of oligolysines ${ }^{125}$ (part $\mathrm{f}$ ); a bovine serum album (BSA)dendron block copolymer coating ${ }^{127}$ (part $\mathbf{g}$ ); a coating comprising DNA peptoids ${ }^{128}$ (part h); and silica-based coatings ${ }^{130}$ (part i). APTES, (3-aminopropyl)triethoxysilane; DMTO, dimethoxytrityloxy; LPEI, linear polyethyleneimine; Nae, $\mathrm{N}$-(2-aminoethyl)glycine; Nte, N-2-(2-(2-methoxyethoxy)ethoxy)ethylglycine; TEOS, tetraethyl orthosilicate; TMAPS, $\mathrm{N}$-trimethoxysilylpropyl-N,N,N-trimethylammonium chloride.

intact on exposure to $10 \mathrm{U}$ of DNase I for $1 \mathrm{~h}$ at room temperature, whereas only $20 \%$ of the native structures remained intact. A peptoid-based coating has also been developed to protect DNA origami octahedral structures against nucleases ${ }^{128}$ (FIG. 6h). Compared with peptides, peptoids provide enhanced protection against proteolytic cleavage ${ }^{129}$. The peptoid sequences contained two types of monomer: positively charged $\mathrm{N}$-(2-aminoethyl) glycine to facilitate electrostatic complexation with the DNA structure and neutral N-2-(2-(2-methoxyethoxy) ethoxy)ethylglycine for surface passivation. In the presence of DNase I, the bare octahedra completely degraded, whereas peptoid protection preserved the structures. To demonstrate the utility in biomedical applications, bovine serum albumin was encapsulated within the DNA octahedra, which protected the encapsulated protein from hydrolysis by trypsin. In another study, a solution-based method was used to coat 24-helixbundle DNA origami nanostructures with a thin layer of silica $^{130}$ (FIG. 6i). This coating enabled the DNA origami structures to withstand degradation by DNase I.

\section{Analysis techniques}

The predominant techniques used to analyse the nuclease digestion of DNA nanostructures are polyacrylamide or agarose gel electrophoresis (PAGE and AGE, respectively), fluorescence, transmission electron microscopy (TEM) and atomic force microscopy (AFM). All these techniques are commonly used to characterize the formation of DNA nanostructures, but gel electrophoresis is the most often-used technique to quantify the reduction in intact structures on incubation with nucleases or body fluids (FIG. 7a). Typically, nanostructures are incubated for different times with nucleases or serum (or with different concentrations of these), and the incubated samples run on PAGE or AGE. The band corresponding to the structure is then quantified to obtain the level of degradation ${ }^{131}$. Fluorescence and Förster resonance energy transfer (FRET) techniques are also often used to quantify degradation of nanostructures ${ }^{106,122}$. Upon degradation of DNA nanostructures conjugated to fluorescent dyes, the fluorophore and the quencher (or the FRET pair) separate, causing an increase in fluorescence levels (FIG. 7b). This increase can be monitored over time to study the degradation kinetics of DNA nanostructures.

Gel electrophoresis and fluorescence techniques provide information on the degradation levels of nanostructures but do not provide information on structural changes. To obtain such structural information, TEM and AFM are used to provide before and after snapshots of DNA nanostructures incubated with body fluids or nucleases $^{111,132}$ (FIG. 7c,d). Real-time AFM was recently used to monitor the degradation of different 2D DNA origami shapes when incubated with nucleases ${ }^{133}$. This technique enables visualization of nanostructures as they degrade and is, thus, useful in determining the parameters for the design of improved DNA-based nanocarriers (for example, in determining whether nucleases affect vertices more than edges).

Overall, gel electrophoresis and fluorescence techniques are the easiest to adapt for most laboratories and provide timed degradation analysis. AFM and TEM require specific instrumentation and training, and are time-consuming, making them the least practical for monitoring the nuclease digestion of DNA nanostructures. The advances in real-time-AFM potentially address the issue of long experimental observation times but is still an expensive instrument not available in most laboratories. There are also challenges associated with the use of gel-based analysis techniques. For example, in the case of cationic block copolymers, polyplexed DNA origami need to be decomplexed (by dextran sulfate, for example) before they can be analysed on a gel (also applicable to TEM) ${ }^{126}$. Moreover, in studies involving FBS or human serum, the serum proteins could cause a background signal in both AGE and TEM, thus necessitating purification of treated samples before analysis.

\section{Mechanism of nuclease resistance}

There is still a lack of understanding of the mechanisms of reported nuclease resistance for different structures or protection strategies. Depending on the type of nuclease used, different parameters, such as DNA sequence, backbone geometry, groove width, curvature and flexibility, can all contribute to nuclease resistance ${ }^{134}$. For DNA nanostructures, the non-native geometries and sizes could have a role in inhibiting enzyme binding, thus decreasing the efficiency of specific or non-specific enzymatic cleavage ${ }^{105}$. Close-packed helices and frequent crossovers in DNA nanostructures can also occlude enzyme binding, thus negating the effect of nucleases ${ }^{22,133}$. Furthermore, nucleases such as DNase I cause distortion on binding to helices ${ }^{135}$, and, thus, the increased stiffness of shorter duplex regions or multi-helical edges within DNA nanostructures might prevent the binding of such enzymes. In the case of different modifications and coatings, strong multivalent interactions of the envelope with the DNA could hinder nuclease adsorption and, thus, reduce the degradation. In DNA origami, the scaffold strand already contains restriction sites. In a study on 2D structures, such as a DNA triangle and rectangle, the position of the restriction site post-folding and the introduction of defects (missing staple strands) affected the overall activity of restriction endonuclease on the structures ${ }^{136}$. In a follow-up computational study, global conformational fluctuations between metastable states of DNA origami structures were shown to affect the reactivity of restriction endonucleases on the structures ${ }^{137}$. Simulations of a 2D DNA origami triangle with four or eight staple 


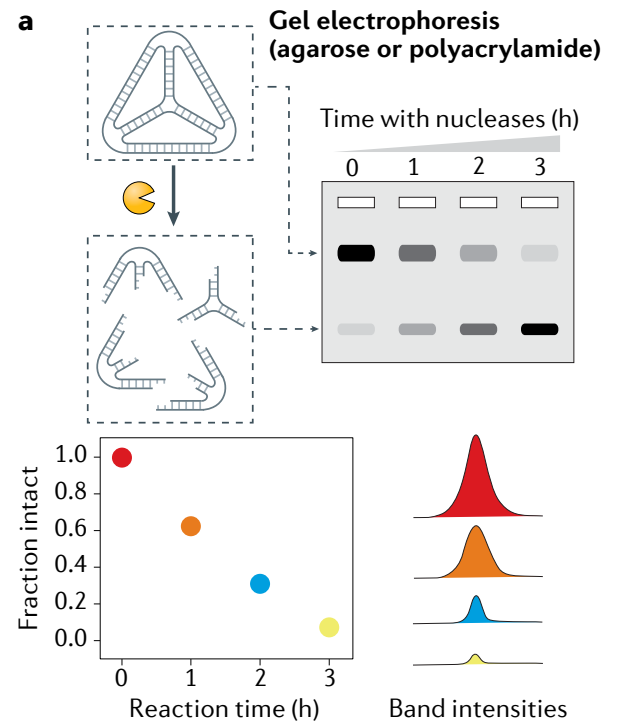

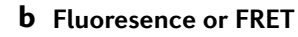
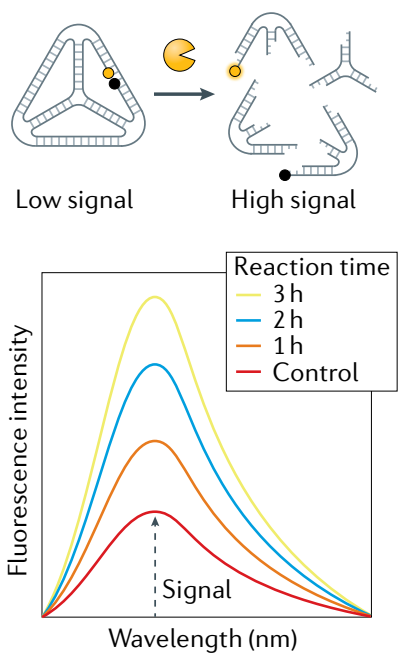

C Atomic force microscopy

d Transmission electron microscopy

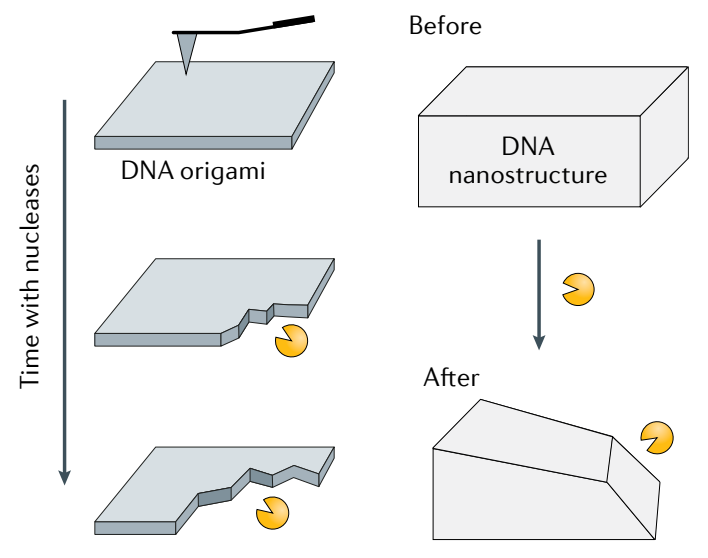

Fig. 7 | Techniques used to analyse nuclease degradation of DNA nanostructures. The main techniques used to analyse DNA nanostructures are polyacrylamide or agarose gel electrophoresis (part a), fluorescence or Förster resonance energy transfer (FRET; part b), atomic force microscopy (AFM; part c) and transmission electron microscopy (TEM; part d).

strands omitted from the structure, each resulting in a metastable assembly, revealed that the accessibility of the enzyme to the structure is dependent on the interconversion between these metastable states. This analysis showed that the reactivity of restriction enzymes is dependent on the steric overlap between the enzyme and the adjacent helices, thus, providing a route to designing nanostructures with higher or lower nuclease resistance.

\section{A checklist for biostability studies}

Design principles. Researchers have designed a large library of DNA nanostructures, each requiring specific assembly conditions. Given this requirement, one has to choose a strategy for modulating the nuclease resistance of a DNA nanostructure on the basis of the design of the underlying DNA assembly. For example, DNA prisms in which the strand termini contained hexaethylene glycol and hexanediol groups showed enhanced nuclease resistance ${ }^{113,116}$, but the same strategy applied to a larger wireframe DNA origami pentagonal bipyramid did not further stabilize the structure in $10 \% \mathrm{FBS}^{110}$. Although there is no general set of rules to make this choice, some studies have noted how the stability numbers reported could apply to similar structures. In DNA origami, most structures share a common scaffold strand (M13) and, thus, have similar GC content if completely double-stranded, eliminating sequence as a factor in stability variations. Therefore, the difference in stability arises from the design of the nanostructures, how closely the helical bundles are packed and the length of the staple strands ${ }^{104}$. Even if the stability reported for an origami structure is not representative for objects built with similar specifications, these results could be useful in designing new objects with an expected robustness. In designing other structures, adapting the edges to be multi-helical domains might increase the persistence length of the wireframe structures and, thus, provide additional stability.
Types of nucleases and concentrations. The nuclease of choice in most studies is DNase I. However, some studies have tested the degradation of DNA nanostructures in the presence of other nucleases, showing that the level of degradation is dependent on the exonuclease or endonuclease used ${ }^{92,104,118}$. In two studies, enzymes such as exonuclease VIII, lambda exonuclease, Mse I restriction endonuclease and T7 exonuclease did not have any effect on DNA origami objects, whereas DNase I, Escherichia coli exonuclease I, exonuclease T, T7 endonuclease and exonuclease III degraded them ${ }^{104,115}$. Similarly, PX DNA showed different levels of resistance to DNase I, exonuclease V, T7 exonuclease and T5 exonuclease; however, PX DNA displayed much higher nuclease resistance than DX or duplex structures in all cases ${ }^{92}$. Thus, although generic trends exist, the activity of different nucleases could differ. The concentration of nucleases tested is also an important factor in determining the extent of degradation. Through calibration of the nuclease levels in FBS by comparing DNA origami nanostructures incubated in 1-20\% FBS and different concentrations of DNase I, it was estimated that typical tissue culture conditions may contain between 256 and 1,024 $\mathrm{U} \mathrm{l}^{-1}$ equivalent of DNase I activity ${ }^{109}$. These studies indicate that it is important to know the specific levels of nucleases in different biofluids and to test relevant amounts of nucleases in such biostability studies.

Reagents. Another factor to consider when testing the stability of DNA nanostructures is the type of serum used and the freeze-thaw protocols. The level of nuclease activity in different FBS lots and frozen aliquots has been observed to vary ${ }^{109}$. In this report, the nuclease activity was highest after initial thawing of the FBS and was lost after a few weeks when FBS-supplemented medium was stored at $4{ }^{\circ} \mathrm{C}\left(\mathrm{REF}^{109}\right)$. Thus, it is important to follow the specific reagent-handling protocol across multiple experiments to validate the nuclease-resistance values 
of different structures. Nuclease activity in body fluids also varies widely between species ${ }^{138,139}$, and studies on DNA nanostructures have also found the stability of nanostructures to vary in sera from different species ${ }^{110}$. Future studies could work with human-derived solutions instead of animal sera to make the results more relevant for human applications.

Choice of protection strategy. The type of application will determine the level of biostability needed and which strategy to use for modulating nuclease resistance. In drug delivery, partial digestion of DNA nanostructures could trigger release of the drug cargo or attached functional moieties (such as fluorophores for tracking). However, slow or delayed degradation of nanostructures could be useful in the spontaneous release of drugs. The addition of nuclease inhibitors or the heat treatment of samples are potential options for biosensing applications in which the sample can be preprocessed before addition of the DNA sensor. However, use of DNA nanostructures in vivo requires strategies that obviate the need to alter the environment, as the addition of external factors might influence other biomolecular processes. Furthermore, the choice of strategy will also depend on the type of biofluid the structures will be in (blood, urine, saliva), and prior knowledge of the types of nucleases present in these fluids and their levels will be useful in biostability studies. Once the stabilization strategy is chosen, it is imperative to test the functionality of these structures after the protection process; chemical modifications or coatings should not affect the binding of sensing elements or targeting moieties to DNA nanostructures. For example, the peptoid coating of DNA origami structures did not affect the encapsulation of cargos such as proteins and nanoparticles within the nanostructure, suggesting potential use in drug delivery ${ }^{128}$. In addition, polyplex micelles comprising cationic polysaccharides have been successfully used to stabilize plasmid DNA for gene therapy ${ }^{140}$, indicating the potential use of similarly stabilized DNA nanostructures.

In vivo stability and immune response. The integrity of DNA nanostructures in vivo affects the immune response in cells or animals. When used as drug carriers, the immune response elicited by intact and degraded nanostructures might differ in some cases, whereas in others, it might be dependent on the total mass of DNA and not the design or integrity of the nanostructures ${ }^{109}$. Thus, care has to be taken to test the intactness of DNA nanostructures in studies in which the specific immune response is important. For example, the oligolysinePEG block copolymer coating of DNA nanostructures had negligible effect on cell viability or enzyme kinetics, indicating minimal immune response in the cells ${ }^{125,141}$. Studies to test in vivo stability and immune response might also require additional functionalities to track the nanostructure through the body or a cellular pathway, and can use newly developed techniques, such as a 'hydroporator', to deliver DNA nanostructures directly into cells for monitoring ${ }^{142}$.

\section{Conclusion}

As DNA nanotechnology moves towards real-life applications, enhancing the stability of nanostructures in biological environments is of increasing importance. The strategies discussed in this Review provide an overview of methods to modulate the nuclease resistance of DNA nanostructures, rendering them more useful in biological applications. There is already a large library of DNA nanostructures available, but future studies will need to focus on upgrading these structures to be application-ready.

The studies discussed herein have used different structures as examples in different environments (different culture media, with or without serum supplement, or in a combination of nucleases). From these studies, it is apparent that DNA nanostructures possess higher nuclease resistance than duplexes, and that all the strategies discussed can enhance this resistance. However, it is difficult to further compare results from these studies, as they report results using different metrics (lifetime, half-life, percentage intact) and use different nanostructures. To facilitate comparison, the DNA nanotechnology research community is encouraged to decide on a set of standardized reporting parameters for nuclease resistance and biostability. Such a system would benefit the generalization of design parameters and the choice of strategy for a specific structure and/or application. Future studies could also explore the effect of the shape and size of DNA nanostructures on nuclease resistance, reports on which are few.

DNA nanostructures have permeated many different fields and are closer to real-life applications than ever before. The ongoing development of stabilization strategies, construction methods, characterization tools and platforms that allow non-experts to design DNA nanostructures ${ }^{143}$ is contributing to the rapid progress towards achieving the potential that DNA nanotechnology promises.

Published online 10 February 2021
1. Seeman, N. C. Nucleic acid junctions and lattices. J. Theor. Biol. 99, 237-247 (1982).

2. Seeman, N. C. et al. New motifs in DNA nanotechnology. Nanotechnology 9, 257-273 (1998).

3. Seeman, N. C. DNA in a material world. Nature $\mathbf{4 2 1}$ 427-431 (2003)

4. Chandrasekaran, A. R. \& Zhuo, R. A 'tile' tale: hierarchical self-assembly of DNA lattices. Appl. Mater. Today 2, 7-16 (2016).

5. Seeman, N. C. DNA Nanotechnology at 40. Nano Lett. 20, 1477-1478 (2020)

6. Seeman, N. C. \& Sleiman, H. F. DNA nanotechnology. Nat. Rev. Mater. 3, 17068 (2018).
7. Xavier, P. L. \& Chandrasekaran, A. R. DNA-based construction at the nanoscale: emerging trends and applications. Nanotechnology 29, 062001 (2018).

8. Hong, F., Zhang, F., Liu, Y. \& Yan, H. DNA origami: scaffolds for creating higher order structures. Chem. Rev. 117, 12584-12640 (2017).

9. Liu, L., Li, Z., Li, Y. \& Mao, C. Rational design and self-assembly of two-dimensional, dodecagonal DNA quasicrystals. J. Am. Chem. Soc. 141, 4248-4251 (2019).

10. He, Y. et al. Hierarchical self-assembly of DNA into symmetric supramolecular polyhedra. Nature 452, 198-201 (2008).
11. Benson, E. et al. DNA rendering of polyhedral meshes at the nanoscale. Nature 523, 441-444 (2015).

12. Andersen, E. S. et al. Self-assembly of a nanoscale DNA box with a controllable lid. Nature 459, 73-76 (2009).

13. Gu, H., Chao, J., Xiao, S.-J. \& Seeman, N. C. A proximity-based programmable DNA nanoscale assembly line. Nature 465, 202-205 (2010).

14. Tikhomirov, G., Petersen, P. \& Qian, L. Fractal assembly of micrometre-scale DNA origami arrays with arbitrary patterns. Nature 552, 67-71 (2017).

15. Chandrasekaran, A. R., Anderson, N., Kizer, M. Halvorsen, K. \& Wang, X. Beyond the fold: emerging 
biological applications of DNA origami. ChemBioChem 17, 1081-1089 (2016)

16. Chandrasekaran, A. R. DNA origami and biotechnology applications: a perspective. J. Chem. Technol. Biotechnol. 91, 843-846 (2016).

17. Chandrasekaran, A. R. \& Levchenko, O. DNA nanocages. Chem. Mater. 28, 5569-5581 (2016).

18. Li, S. et al. A DNA nanorobot functions as a cancer therapeutic in response to a molecular trigger in vivo. Nat. Biotechnol. 36, 258-264 (2018)

19. Chandrasekaran, A. R. et al. Cellular microRNA detection with miRacles: microRNA-activated conditional looping of engineered switches. Sci. Adv. 5, eaau9443 (2019)

20. Bhatia, D., Surana, S., Chakraborty, S., Koushika, S. P. \& Krishnan, Y. A synthetic icosahedral DNA-based host-cargo complex for functional in vivo imaging. Nat. Commun. 2, 339 (2011).

21. Shi, S. et al. Modulation of chondrocyte motility by tetrahedral DNA nanostructures. Cell Prolif. 50, e12368 (2017)

22. Xiao, M. et al. Rationally engineered nucleic acid architectures for biosensing applications. Chem. Rev. 119, 11631-11717 (2019).

23. Ye, D., Zuo, X. \& Fan, C. DNA nanotechnology-enabled interfacial engineering for biosensor development. Annu. Rev. Anal. Chem. 11, 171-195 (2018).

24. Chandrasekaran, A. R., Wady, H. \& Subramanian, H. K. K. Nucleic acid nanostructures for chemical and biological sensing. Small 12 , 2689-2700 (2016).

25. Hu, O., Li, H., Wang, L., Gu, H. \& Fan, C. DNA nanotechnology-enabled drug delivery systems. Chem. Rev. 119, 6459-6506 (2019)

26. Madhanagopal, B. R., Zhang, S., Demirel, E., Wady, H. \& Chandrasekaran, A. R. DNA nanocarriers: programmed to deliver. Trends Biochem. Sci. 43, 997-1013 (2018)

27. Linko, V., Ora, A. ¿ Kostiainen, M. A. DNA nanostructures as smart drug-delivery vehicles and molecular devices. Trends Biotechnol. 33, 586-594 (2015).

28. Jiang, D., England, C. G. \& Cai, W. DNA nanomaterials for preclinical imaging and drug delivery. J. Control. Release 239, 27-38 (2016)

29. Mathur, D. \& Medintz, I. L. The growing development of DNA nanostructures for potential healthcarerelated applications. Adv. Healthc. Mater. 8, 1801546 (2019).

30. Chakraborty, K., Veetil, A. T., Jaffrey, S. R. \& Krishnan, Y. Nucleic acid-based nanodevices in biological imaging. Annu. Rev. Biochem. 85, 349-373 (2016).

31. Rajwar, A., Kharbanda, S., Chandrasekaran, A. R Gupta, S. \& Bhatia, D. Designer, programmable 3D DNA nanodevices to probe biological systems. ACS Appl. Bio Mater. 3, 7265-7277 (2020).

32. Zhao, N., Chen, Y., Chen, G. \& Xiao, Z. Artificial cells based on DNA nanotechnology. ACS Appl. Bio Mater. 3, 3928-3934 (2020).

33. Kuzuya, A. \& Ohya, Y. DNA nanostructures as scaffolds for metal nanoparticles. Polym. J. 44 452-460 (2012).

34. Chandrasekaran, A. R. Programmable DNA scaffolds for spatially-ordered protein assembly. Nanoscale 8 4436-4446 (2016).

35. Bhatia, D. et al. Icosahedral DNA nanocapsules by modular assembly. Angew. Chem. Int. Ed. $\mathbf{4 8}$ 4134-4137 (2009)

36. He, Y., Chen, Y., Liu, H., Ribbe, A. E. \& Mao, C. Self-assembly of hexagonal DNA two-dimensional (2D) arrays. J. Am. Chem. Soc. 127, 12202-12203 (2005).

37. Rothemund, P. W. K. Folding DNA to create nanoscale shapes and patterns. Nature 440, 297-302 (2006).

38. Ke, Y., Ong, L. L., Shih, W. M. \& Yin, P. Threedimensional structures self-assembled from DNA bricks. Science 338, 1177-1183 (2012).

39. Chandrasekaran, A. R. \& Halvorsen, K. Controlled disassembly of a DNA tetrahedron using strand displacement. Nanoscale Adv. 1, 969-972 (2019).

40. Pei, H. et al. Reconfigurable three-dimensional DNA nanostructures for the construction of intracellular logic sensors. Angew. Chem. Int. Ed. 51, 9020-9024 (2012)

41. Douglas, S. M., Bachelet, I. \& Church, G. M. A logic-gated nanorobot for targeted transport of molecular payloads. Science 335, 831-834 (2012).

42. Dittmer, W. U., Reuter, A. \& Simmel, F. C. A DNAbased machine that can cyclically bind and release thrombin. Angew. Chem. Int. Ed. 43, 3550-3553 (2004).
43. Modi, S. et al. A DNA nanomachine that maps spatial and temporal $\mathrm{pH}$ changes inside living cells. Nat. Nanotechnol. 4, 325-330 (2009).

44. Idili, A., Vallée-Bélisle, A. \& Ricci, F. Programmable pH-triggered DNA nanoswitches. J. Am. Chem. Soc 136, 5836-5839 (2014).

45. Juul, S. et al. Temperature-controlled encapsulation and release of an active enzyme in the cavity of a selfassembled DNA nanocage. ACS Nano 7, 9724-9734 (2013).

46. Kohman, R. E. \& Han, X. Light sensitization of DNA nanostructures via incorporation of photo-cleavable spacers. Chem. Commun. 51, 5747-5750 (2015).

47. Chandrasekaran, A. R., Punnoose, J. A., Valsangkar, V., Sheng, J. \& Halvorsen, K. Integration of a photocleavable element into DNA nanoswitches. Chem. Commun. 55, 6587-6590 (2019).

48. Pinheiro, A. V., Han, D., Shih, W. M. \& Yan, H. Challenges and opportunities for structural DNA nanotechnology. Nat. Nanotechnol. 6, 763-772 (2011)

49. Jones, M. R., Seeman, N. C. \& Mirkin, C. A. Programmable materials and the nature of the DNA bond. Science 347, 1260901 (2015)

50. Dunn, K. E. The business of DNA nanotechnology: commercialization of origami and other technologies. Molecules 25, 377 (2020).

51. Linko, V. \& Dietz, H. The enabled state of DNA nanotechnology. Curr. Opin. Biotechnol. 24, 555-56 (2013).

52. Kershner, R. J. et al. Placement and orientation of individual DNA shapes on lithographically patterned surfaces. Nat. Nanotechnol. 4 557-561 (2009).

53. Takabayashi, S. et al. Boron-implanted silicon substrates for physical adsorption of DNA origami. Int. J. Mol. Sci. 19, 2513 (2018)

54. Qian, L. \& Winfree, E. Scaling up digital circuit computation with DNA strand displacement cascades. Science 332, 1196-1201 (2011)

55. Erlich, Y. \& Zielinski, D. DNA fountain enables a robust and efficient storage architecture. Science 355 950-954 (2017).

56. Sun, W. et al. Casting inorganic structures with DNA molds. Science 346, 1258361 (2014)

57. Weichelt, R., Ye, J., Banin, U., Eychmüller, A. \& Seidel, R. DNA-mediated self-assembly and metallization of semiconductor nanorods for the fabrication of nanoelectronic interfaces. Chem. Eur. J. 25, 9012-9016 (2019)

58. Liao, S. \& Seeman, N. C. Translation of DNA signals into polymer assembly instructions. Science 306 2072-2074 (2004).

59. Chen, Y. \& Mao, C. Reprogramming DNA-directed reactions on the basis of a DNA conformational change. J. Am. Chem. Soc. 126, 13240-1324 (2004).

60. Martin, T. G. et al. Design of a molecular support for cryo-EM structure determination. Proc. Natl Acad. Sci. USA 113, E7456-E7463 (2016).

61. Douglas, S. M., Chou, J. J. \& Shih, W. M. DNA nanotube-induced alignment of membrane proteins for NMR structure determination. Proc. Natl Acad. Sci. USA 104, 6644-6648 (2007).

62. Hernandez, C. et al. Self-assembly of 3D DNA crystals containing a torsionally stressed component. Cell Chem. Biol. 24, 1401-1406.e2 (2017).

63. Chandrasekaran, A. R. et al. DNA nanotechnology approaches for microRNA detection and diagnosis. Nucleic Acids Res. 47, 10489-10505 (2019).

64. Coleridge, E. L. \& Dunn, K. E. Assessing the cost-effectiveness of DNA origami nanostructures for targeted delivery of anti-cancer drugs to tumours. Biomed. Phys. Eng. Express 6, 065030 (2020).

65. Zhou, L. et al. Programmable low-cost DNA-based platform for viral RNA detection. Sci. Adv. 6 , eabc6246 (2020).

66. Li, Y., Cu, Y. T. H. \& Luo, D. Multiplexed detection of pathogen DNA with DNA-based fluorescence nanobarcodes. Nat. Biotechnol. 23, 885-889 (2005).

67. Chandrasekaran, A. R. et al. DNA nanoswitch barcodes for multiplexed biomarker profiling. Nano Lett. 21, 469-475 (2021)

68. Porchetta, A. et al. Programmable nucleic acid nanoswitches for the rapid, single-step detection of antibodies in bodily fluids. J. Am. Chem. Soc. 140 947-953 (2018)

69. Liang, L. et al. Single-particle tracking and modulation of cell entry pathways of a tetrahedral DNA nanostructure in live cells. Angew. Chem. Int. Ed. $\mathbf{5 3}$ 7745-7750 (2014).
70. Hu, R. et al. DNA nanoflowers for multiplexed cellular imaging and traceable targeted drug delivery. Angew. Chem. Int. Ed. 53, 5821-5826 (2014).

71. Valsangkar, V. A. et al. Click and photo-release dual-functional nucleic acid nanostructures. Chem. Commun. 55, 9709-9712 (2019).

72. Messaoudi, S., Greschner, A. A. \& Gauthier, M. A. Progress toward absorption, distribution, metabolism, elimination, and toxicity of DNA nanostructures. Adv. Ther. 2, 1900144 (2019).

73. Schüller, V. J. et al. Cellular immunostimulation by $\mathrm{CpG}$-sequence-coated DNA origami structures. ACS Nano 5, 9696-9702 (2011).

74. Rosier, B. J. H. M. et al. Incorporation of native antibodies and Fc-fusion proteins on DNA nanostructures via a modular conjugation strategy. Chem. Commun. 53, 7393-7396 (2017).

75. Stewart, J. M. et al. Programmable RNA microstructures for coordinated delivery of siRNAs. Nanoscale 8, 17542-17550 (2016).

76. Fakhoury, J. J., McLaughlin, C. K., Edwardson, T. W., Conway, J. W. \& Sleiman, H. F. Development and characterization of gene silencing DNA cages. Biomacromolecules 15, 276-282 (2014).

77. Liu, X. et al. A DNA nanostructure platform for directed assembly of synthetic vaccines. Nano Lett. 12, 4254-4259 (2012).

78. Song, L. et al. DNA origami/gold nanorod hybrid nanostructures for the circumvention of drug resistance. Nanoscale 9, 7750-7754 (2017).

79. Aldaye, F. A., Senapedis, W. T., Silver, P. A. \& Way, J. C. A structurally tunable DNA-based extracellular matrix. J. Am. Chem. Soc. 132, 14727-14729 (2010).

80. Zhou, M. et al. Effect of tetrahedral DNA nanostructures on proliferation and osteo/odontogenic differentiation of dental pulp stem cells via activation of the notch signaling pathway. Nanomed. Nanotechnol. Biol. Med. 14, 1227-1236 (2018).

81. Stephanopoulos, N. et al. Bioactive DNA-peptide nanotubes enhance the differentiation of neural stem cells into neurons. Nano Lett. 15, 603-609 (2015).

82. Zhang, Q. et al. Anti-inflammatory and antioxidative effects of tetrahedral DNA nanostructures via the modulation of macrophage responses. ACS Appl. Mater. Interfaces 10, 3421-3430 (2018).

83. Peng, $\mathrm{O}$, et al. Understanding the biomedical effects of the self-assembled tetrahedral DNA nanostructure on living cells. ACS Appl. Mater. Interfaces $\mathbf{8}$, 12733-12739 (2016)

84. Jia, R. et al. Aptamer-functionalized activatable DNA tetrahedron nanoprobe for PIWI-interacting RNA imaging and regulating in cancer cells. Anal. Chem 91, 15107-15113 (2019).

85. Wang, S., Xia, M., Liu, J., Zhang, S. \& Zhang, X Simultaneous imaging of three tumor-related mRNAs in living cells with a DNA tetrahedron-based multicolor nanoprobe. ACS Sens. 2, 735-739 (2017).

86. Liu, X., Wu, L., Wang, L. \& Jiang, W. A dual-targeting DNA tetrahedron nanocarrier for breast cancer cell imaging and drug delivery. Talanta 179, 356-363 (2018).

87. Schmied, J. J. et al. DNA origami-based standards for quantitative fluorescence microscopy. Nat. Protoc. 9 , 1367-1391 (2014).

88. Jungmann, R. et al. Multiplexed 3D cellular superresolution imaging with DNA-PAINT and exchangePAINT. Nat. Methods 11, 313-318 (2014).

89. Allentoft, M. E. et al. The half-life of DNA in bone: measuring decay kinetics in 158 dated fossils. Proc. R. Soc. B Biol. Sci. 279, 4724-4733 (2012).

90. Rajendran, A., Endo, M., Katsuda, Y., Hidaka, K \& Sugiyama, H. Photo-cross-linking-assisted thermal stability of DNA origami structures and its application for higher-temperature self-assembly. J. Am. Chem. Soc. 133, 14488-14491 (2011)

91. Kielar, C. et al. On the stability of DNA origami nanostructures in low-magnesium buffers. Angew. Chem. Int. Ed. 57, 9470-9474 (2018).

92. Chandrasekaran, A. R. et al. Exceptional nuclease resistance of paranemic crossover (PX) DNA and crossover-dependent biostability of DNA motifs. J. Am. Chem. Soc. 142, 6814-6821 (2020).

93. Ramakrishnan, S., Krainer, G., Grundmeier, G. Schlierf, M. \& Keller, A. Structural stability of DNA origami nanostructures in the presence of chaotropic agents. Nanoscale 8, 10398-10405 (2016).

94. Myhrvold, C., Dai, M., Silver, P. A. \& Yin, P. Isothermal self-assembly of complex DNA structures under diverse and biocompatible conditions. Nano Lett. 13 4242-4248 (2013). 
95. Salvati, A. et al. Transferrin-functionalized nanoparticles lose their targeting capabilities when a biomolecule corona adsorbs on the surface. Nat. Nanotechnol. 8, 137-143 (2013).

96. Yang, W. Nucleases: diversity of structure, function and mechanism. Q. Rev. Biophys. 44, 1-93 (2011).

97. Champoux, J. J. DNA topoisomerases: structure, function, and mechanism. Annu. Rev. Biochem. 70, 369-413 (2001)

98. Grindley, N. D. F., Whiteson, K. L. \& Rice, P. A. Mechanisms of site-specific recombination. Annu. Rev. Biochem. 75, 567-605 (2006).

99. Patel, A. A. \& Steitz, J. A. Splicing double: insights from the second spliceosome. Nat. Rev. Mol. Cell Biol. 4, 960-970 (2003)

100. Barry, M. E. et al. Role of endogenous endonucleases and tissue site in transfection and $\mathrm{CpG}$-mediated immune activation after naked DNA injection. Hum. Gene Ther. 10, 2461-2480 (1999).

101. Samejima, K. \& Earnshaw, W. C. Trashing the genome: the role of nucleases during apoptosis. Nat. Rev. Mol. Cell Biol 6, 677-688 (2005).

102. Koizumi, T. Deoxyribonuclease II (DNase II) activity in mouse tissues and body fluids. Exp. Anim. 44, 169-171 (1995)

103. Dietz, H., Douglas, S. M. \& Shih, W. M. Folding DNA into twisted and curved nanoscale shapes. Science 325, 725-730 (2009).

104. Castro, C. E. et al. A primer to scaffolded DNA origami. Nat. Methods 8, 221-229 (2011)

105. Keum, J.-W. \& Bermudez, H. Enhanced resistance of DNA nanostructures to enzymatic digestion. Chem. Commun. 7036-7038 (2009).

106. Goltry, S. et al. DNA topology influences molecular machine lifetime in human serum. Nanoscale 7 10382-10390 (2015)

107. Yurke, B., Turberfield, A. J., Mills, A. P. Jr, Simmel, F. C. ¿ Neumann, J. L. A DNA-fuelled molecular machine made of DNA. Nature 406, 605-608 (2000).

108. Wang, X. et al. Paranemic crossover DNA: there and back again. Chem. Rev. 119, 6273-6289 (2019).

109. Hahn, J., Wickham, S. F. J., Shih, W. M. \& Perrault, S. D. Addressing the instability of DNA nanostructures in tissue culture. ACS Nano 8, 8765-8775 (2014).

110. Wamhoff, E.-C. et al. Controlling wireframe DNA origami nuclease degradation with minor groove binders. Preprint at bioRxiv https://www.biorxiv.org/ content/10.1101/2020.05.24.110783v1 full (2020).

111. Li, Y. et al. Universal pH-responsive and metal-ion-free self-assembly of DNA nanostructures. Angew. Chem. Int. Ed. 57, 6892-6895 (2018).

112. Li, Y. \& Schulman, R. DNA nanostructures that self-heal in serum. Nano Lett. 19, 3751-3760 (2019).

113. Conway, J. W., McLaughlin, C. K., Castor, K. J. ¿ Sleiman, H. DNA nanostructure serum stability: greater than the sum of its parts. Chem. Commun. 49, 1172-1174 (2013)

114. Cassinelli, V. et al. One-step formation of "chain armor"-stabilized DNA nanostructures. Angew. Chem. Int. Ed. 54, 7795-7798 (2015).

115. Gerling, T., Kube, M., Kick, B. \& Dietz, H. Sequenceprogrammable covalent bonding of designed DNA assemblies. Sci. Adv. 4, eaau 1157 (2018).
116. Lacroix, A., Vengut-Climent, E., de Rochambeau, D. \& Sleiman, H. F. Uptake and fate of fluorescently labeled DNA nanostructures in cellular environments: a cautionary tale. ACS Cent. SCi. 5, 882-891 (2019).

117. Lin, C. et al. Mirror image DNA nanostructures for chiral supramolecular assemblies. Nano Lett. 9 433-436 (2009)

118. Liu, Q. et al. Enhanced stability of DNA nanostructures by incorporation of unnatural base pairs. ChemPhysChem 18, 2977-2980 (2017).

119. Chandrasekaran, A. R. et al. Hybrid DNA/RNA nanostructures with 2'-5' linkages. Nanoscale 12 21583-21590 (2020).

120. Lacroix, A., Edwardson, T. G. W., Hancock, M. A., Dore, M. D. \& Sleiman, H. F. Development of DNA nanostructures for high-affinity binding to human serum albumin. J. Am. Chem. Soc. 139, 7355-7362 (2017).

121. Kim, Y. \& Yin, P. Enhancing biocompatible stability of DNA nanostructures using dendritic oligonucleotides and brick motifs. Angew. Chem. Int. Ed. 59, 700-703 (2020).

122. Perrault, S. D. \& Shih, W. M. Virus-inspired membrane encapsulation of DNA nanostructures to achieve in vivo stability. ACS Nano 8, 5132-5140 (2014).

123. Ahmadi, Y., Llano, E. D. \& Barišić, I. (Poly)cationinduced protection of conventional and wireframe DNA origami nanostructures. Nanoscale 10 7494-7504 (2018).

124. Ponnuswamy, N. et al. Oligolysine-based coating protects DNA nanostructures from low-salt denaturation and nuclease degradation. Nat. Commun. 8, 15654 (2017).

125. Anastassacos, F. M., Zhao, Z., Zeng, Y. \& Shih, W. M. Glutaraldehyde cross-linking of oligolysines coating DNA origami greatly reduces susceptibility to nuclease degradation. J. Am. Chem. Soc. 142, 3311-3315 (2020).

126. Agarwal, N. P., Matthies, M., Gür, F. N., Osada, K $\&$ Schmidt, T. L. Block copolymer micellization as a protection strategy for DNA origami. Angew. Chem. Int. Ed. 56, 5460-5464 (2017).

127. Auvinen, H. et al. Protein coating of DNA nanostructures for enhanced stability and immunocompatibility. Adv. Healthc. Mater. 6 1700692 (2017).

128. Wang, S.-T. et al. DNA origami protection and molecular interfacing through engineered sequence defined peptoids. Proc. Natl Acad. Sci. USA 117, 6339-6348 (2020).

129. Miller, S. M. et al. Proteolytic studies of homologous peptide and $\mathrm{N}$-substituted glycine peptoid oligomers. Bioorg. Med. Chem. Lett. 4, 2657-2662 (1994).

130. Nguyen, M.-K. et al. Ultrathin silica coating of DNA origami nanostructures. Chem. Mater. 32 6657-6665 (2020).

131. Chandrasekaran, A. R. \& Halvorsen, K. Nuclease degradation analysis of DNA nanostructures using gel electrophoresis. Curr. Protoc. Nucleic Acid. Chem. 82 e115 (2020)

132. Zagorovsky, K., Chou, L. Y. T. \& Chan, W. C. W. Controlling DNA-nanoparticle serum interactions. Proc. Natl. Acad. Sci. USA 113, 13600-13605 (2016).
133. Ramakrishnan, S. et al. Real-time observation of superstructure-dependent DNA origami digestion by DNase I using high-speed atomic force microscopy. ChemBioChem 20, 2818-2823 (2019).

134. Suck, D. DNA recognition by structure-selective nucleases. Biopolymers 44, 405-421 (1997).

135. Hogan, M. E., Roberson, M. W. \& Austin, R. H. DNA flexibility variation may dominate DNase I cleavage. Proc. Natl. Acad. Sci. USA 86, 9273-9277 (1989)

136. Stopar, A., Coral, L., Di Giacomo, S., Adedeji, A. F. \& Castronovo, M. Binary control of enzymatic cleavage of DNA origami by structural antideterminants. Nucleic Acids Res. 46, 995-1006 (2018).

137. Suma, A., Stopar, A., Nicholson, A. W., Castronovo, M $\&$ Carnevale, V. Global and local mechanical properties control endonuclease reactivity of a DNA origami nanostructure. Nucleic Acids Res. 48, 4672-4680 (2020).

138. Shaw, J.-P., Kent, K., Bird, J., Fishback, J. \& Froehler, B. Modified deoxyoligonucleotides stable to exonuclease degradation in serum. Nucleic Acids Res. 19, 747-750 (1991)

139. Kurnick, N. B. Desoxyribonuclease activity of sera of man and some other species. Arch. Biochem. Biophys. 43, 97-107 (1953).

140. Osada, K. Development of functional polyplex micelles for systemic gene therapy. Polym. J. 46, 469-475 (2014).

141. Kiviaho, J. K. et al. Cationic polymers for DNA origami coating - examining their binding efficiency and tuning the enzymatic reaction rates. Nanoscale $\mathbf{8}$, 11674-11680 (2016).

142. Kizer, M. E. et al. Hydroporator: a hydrodynamic cell membrane perforator for high-throughput vector-free nanomaterial intracellular delivery and DNA origami biostability evaluation. Lab Chip 19, 1747-1754 (2019).

143. Jun, H. et al. Autonomously designed free-form 2D DNA origami. Sci. Adv. 5, eaav0655 (2019).

144. Goodman, R. P. et al. Rapid chiral assembly of rigid DNA building blocks for molecular nanofabrication Science 310, 1661-1665 (2005).

145. Winfree, E. Liu, F, Wenzler, L. A. \& Seeman, N. C. Design and self-assembly of two-dimensional DNA crystals. Nature 394, 539-544 (1998).

\section{Acknowledgements}

The author thanks B.R. Madhanagopal and S. Selvam for critical reading and comments on the manuscript, as well as $J$. Mathivanan for help preparing the ChemDraw images of the chemical structures in the figures.

Competing interests

The author declares no competing interests.

Peer review information

Nature Reviews Chemistry thanks K. Salaita, who co-reviewed with A. Bazrafshan, and the other anonymous, reviewer(s) for their contribution to the peer review of this work.

\section{Publisher's note}

Springer Nature remains neutral with regard to jurisdictional claims in published maps and institutional affiliations.

(c) Springer Nature Limited 2021 